Review

\title{
Optical Properties and Plasmonic Performance of Titanium Nitride
}

\section{Panos Patsalas ${ }^{1, *}$, Nikolaos Kalfagiannis ${ }^{2}$ and Spyros Kassavetis ${ }^{1,3}$}

1 Department of Physics, Aristotle University of Thessaloniki, Thessaloniki GR-54124, Greece; E-Mail: skasa@physics.auth.gr

2 School of Science and Technology, Nottingham Trent University, Nottingham NG11 8NS, UK; E-Mail: nikolaos.kalfagiannis@ntu.ac.uk

3 Department of Materials Science and Engineering, University of Ioannina, Ioannina GR-45110, Greece

* Author to whom correspondence should be addressed; E-Mail: ppats@physics.auth.gr; Tel.: +30-2310-998298.

Academic Editor: Gururaj Naik

Received: 24 April 2015 / Accepted: 25 May 2015 / Published: 29 May 2015

\begin{abstract}
Titanium nitride (TiN) is one of the most well-established engineering materials nowadays. TiN can overcome most of the drawbacks of palsmonic metals due to its high electron conductivity and mobility, high melting point and due to the compatibility of its growth with Complementary Metal Oxide Semiconductor (CMOS) technology. In this work, we review the dielectric function spectra of TiN and we evaluate the plasmonic performance of TiN by calculating (i) the Surface Plasmon Polariton (SPP) dispersion relations and (ii) the Localized Surface Plasmon Resonance (LSPR) band of TiN nanoparticles, and we demonstrate a significant plasmonic performance of TiN.
\end{abstract}

Keywords: titanium nitride; optical properties; ellipsometry; plasmonics; polaritonics

\section{Introduction}

Titanium nitride (TiN) is one of the most well-established engineering materials nowadays. It has been considered since the early 1970 s as a superhard material for protective coatings [1-4] and, as such, has been industrially implemented. Its electronic properties were also extensively studied, as they 
are critical for alternative applications such as diffusion barriers in microelectronic devices [5-9], decorative coatings with bright golden color [10-13], ohmic contacts on III-nitride semiconductors [14-21] and Schottky contacts on $\mathrm{Si}$ [22,23]. Great emphasis has been given to the control of the microstructure of TiN films [24-29], which are critical for its mechanical and electronic performance. In addition to its electronic properties, TiN is appealing for electronic devices due to its compatibility with CMOS technology, because of its high electron mobility and refractory character [30,31].

An emerging field of applications for TiN is plasmonics, the science and technology of interactions of metallic nanostructures with light. In particular, the Surface Plasmon Polariton (SPP) modes on planar interfaces and the Localized Surface Plasmon Resonance (LSPR) in metallic nanoparticles are two unique phenomena that manifest exclusively at the nanoscale [32-40]. Plasmonics promise radical breakthroughs in electronic devices [41-44], biosensing [45-49], catalysis and photochemistry [50-53], solar energy harvesting [54-61], photo-detection [62-64], and optical storage of information [65-70], and open new pathways for the implementation of TiN in new sectors.

The most popular plasmonic metals are gold and silver. However, their melting point is low, especially when in nanoparticle form [71-73], making them unstable for photothermal and hot electron devices; their conduction electron mobility is very low, and, consequently, they exhibit high conduction electron losses [74,75]. TiN can overcome all these obstacles due to its high electron conductivity and mobility [14,19,30,31], high melting point and low work function, and due to the compatibility of its growth with CMOS technology, which enables its easy integration and upscaling in realistic, mainstream electronic devices.

In this work, we review the fundamental properties of TiN and its dielectric function spectra extracted from an extended literature survey of reported ellipsometry and reflectivity spectra. As a result, we critically compare the reported electronic properties (such as resistivity/mean free path, and conduction electron density-via the unscreened plasma energy). We evaluate the plasmonic performance of TiN by calculating (i) the SPP dispersion relations at planar TiN/dielectric interfaces; and (ii) the LSPR band of TiN nanoparticles based on the dielectric functions of bulk TiN. Finally, we demonstrate that the plasmonic response of nanoparticles of $\mathrm{TiN}$ is equivalent, if not superior, to that of nanoparticles of noble metals.

\section{Results and Discussion}

\subsection{Fundamental Features and Methods of Growth}

TiN belongs to the transition metals of the group IVb of the periodic table of elements. As such, it has four valence electrons and their configuration is $3 d^{2} 4 s^{2}$. Ti forms bonds with $\mathrm{N}$ atoms (valence electronic configuration $2 \mathrm{~s}^{2} 2 \mathrm{p}^{3}$ ). While various nitride phases such as the $\mathrm{Ti}_{2} \mathrm{~N}$ [76,77] and $\mathrm{Ti}_{3} \mathrm{~N}_{4}[78,79]$ were reported, the most stable and durable nitrides of these metals are those in the cubic rocksalt B1-TiN structure, also called $\delta$-TiN. The B1-TiN is characterized by gold-like yellow color [10-13], high hardness [1-4], electrical conductivity [15,19], and refractory character. Its electronic conductivity is due to the partially filled valence Ti-3d orbitals that are not completely hybridized with the $\mathrm{N}-2 p$ electrons [80-82]. 
A wide variety of fabrication techniques have been used for the growth of B1-TiN films, such as Magnetron Sputtering (MS) [83-90], Cathodic Vacuum Arc (CVA) [91-93], Chemical Vapor Deposition (CVD) [94,95], Atomic Layer Deposition (ALD) [96,97], Pulsed Laser Deposition [15,16,98,99], Ion Beam Assisted Deposition (IBAD) [100] and High Power Impulse Magnetron Sputtering (HIPIMS) [101]. The numerous works on the growth of B1-TiN led to an unprecedented understanding and control of its microstructural features, such as the grain size, orientation, columnar or globular type of growth, etc. [102-107].

\subsection{Optical Properties of TiN Films}

The optical properties of B1-TiN, which are relevant to plasmonic applications, have been also a subject of intense experimental research using mostly spectroscopic ellipsometry (SE) in all of its varieties, and spectral reflectivity measurements usually at normal incidence [14-16,18,19,82,108-133]. SE measures the ellispometric angles $\Psi-\Delta$, which are associated with the ratio $\rho_{f}$ of the Fresnel reflection coefficients for $s$ - and $p$-polarization [134]:

$$
\rho_{\mathrm{f}}=\tan \psi \cdot e^{i \Delta}
$$

Then, the real and imaginary parts of the dielectric function $\tilde{\varepsilon}=\varepsilon_{1}+i \varepsilon_{2}$ can be analytically calculated from $\rho_{f}$ and the angle of incidence $\phi$ (usually in the range $55^{\circ}-75^{\circ}$ ) [134]:

$$
\tilde{\varepsilon}=\sin ^{2} \phi \cdot\left[1+\tan ^{2} \varphi\left(\frac{1-\rho_{\mathrm{f}}}{1+\rho_{\mathrm{f}}}\right)^{2}\right]
$$

On the other hand, the real and imaginary parts of the complex refractive index $\tilde{n}=n+i k$ can be extracted from the spectral reflectivity measurements at normal incidence $R$ via the relations [135]:

$$
n=\frac{1-R}{1+R-2 \cos \theta \sqrt{R}}, k=\frac{-2 \sin \theta \sqrt{R}}{1+R-2 \cos \theta \sqrt{R}}
$$

where $\theta$ is the phase change due to reflectivity, which is determined by Kramers-Kronig integration [135]:

$$
\theta\left(\omega_{0}\right)=\frac{1}{\pi} \int_{0}^{\infty} \ln \left|\frac{\omega+\omega_{0}}{\omega-\omega_{0}}\right| \frac{d \ln \sqrt{R(\omega)}}{d \omega} d \omega
$$

Alternatively, the $n, k$ can be also determined by fitting the spectral reflectivity curves using specific dispersion relation models, as we will discuss below. The complex dielectric function and the complex refractive index are equivalent and interchangeable, as they are analytically correlated:

$$
\varepsilon_{1}=n^{2}-k^{2}, \varepsilon_{2}=2 n k
$$

In the case of a thin film grown on a bulk substrate, the measured spectra by SE or spectral reflectivity accounts the effect of the substrate and film's thickness, in addition to the film's optical properties. Opaque TiN films should be thicker than $100 \mathrm{~nm}$ in order to measure directly their complex dielectric function, without any contribution from the substrate; else, a three-phase model (air/homogeneous film/semi-infinite substrate) [136] is required to determine the complex dielectric function. 
In this work, we retrieved and critically review the optical data of TiN from [108-128]. Table 1 lists the samples grown and the spectra measured by numerous groups worldwide regarding the optical properties of TiN. It includes information relevant to the growth conditions, morphology, and optical measurement conditions, as well as the corresponding references [108-128]. In order to have a unified picture and compare all the available data in the literature, when the $n, k$ values are reported in the original references, we calculated the $\varepsilon_{1}, \varepsilon_{2}$ values using Equation (5). The $\varepsilon_{1}, \varepsilon_{2}$ from [108-123] are presented in Figure 1. There is a substantial variation and scattering of the reported experimental spectra due to the sensitivity of TiN's optical performance to various factors, such as stoichiometry $([\mathrm{N}] /[\mathrm{Ti}]$ ratio), impurities (residual oxygen in sputter growth or chlorine in CVD growth, post growth oxidation), grain size (which affects the mean free path of the conduction electrons, as we will discuss in more detail below) and density/porosity (which affect the conduction electron density [120]).

The $\varepsilon_{1}$ spectra have attracted particular attention, and are considered to be characteristic of the TiN's chemical and structural quality [117]. The first spectral region (up to $3 \mathrm{eV}$ ) is characterized by negative values of $\varepsilon_{1}$ due to the interaction of light with the conduction electrons of TiN, i.e., due to intraband absorption. In particular, and of major importance, is the screened plasma energy $E_{\mathrm{ps}}=\hbar \omega_{\mathrm{ps}}$, which is the spectral energy at which TiN's $\varepsilon_{1}=0 . E_{\mathrm{ps}}$ may be affected by both the intraband and interband characteristics and ranges from 2 to $2.95 \mathrm{eV}$. $\mathrm{E}_{\mathrm{ps}}$ was reported to be an indicator of the stoichiometry of $\mathrm{TiN}_{\mathrm{x}}$, and gets the value $2.65 \mathrm{eV}$ for $x=1$ [117]; despite of the efficiency of this phenomenological observation, $E_{\mathrm{ps}}$ does not have any other solid physical meaning but it is critical for the plasmonic behavior of TiN-based SPP devices, as we will show below.
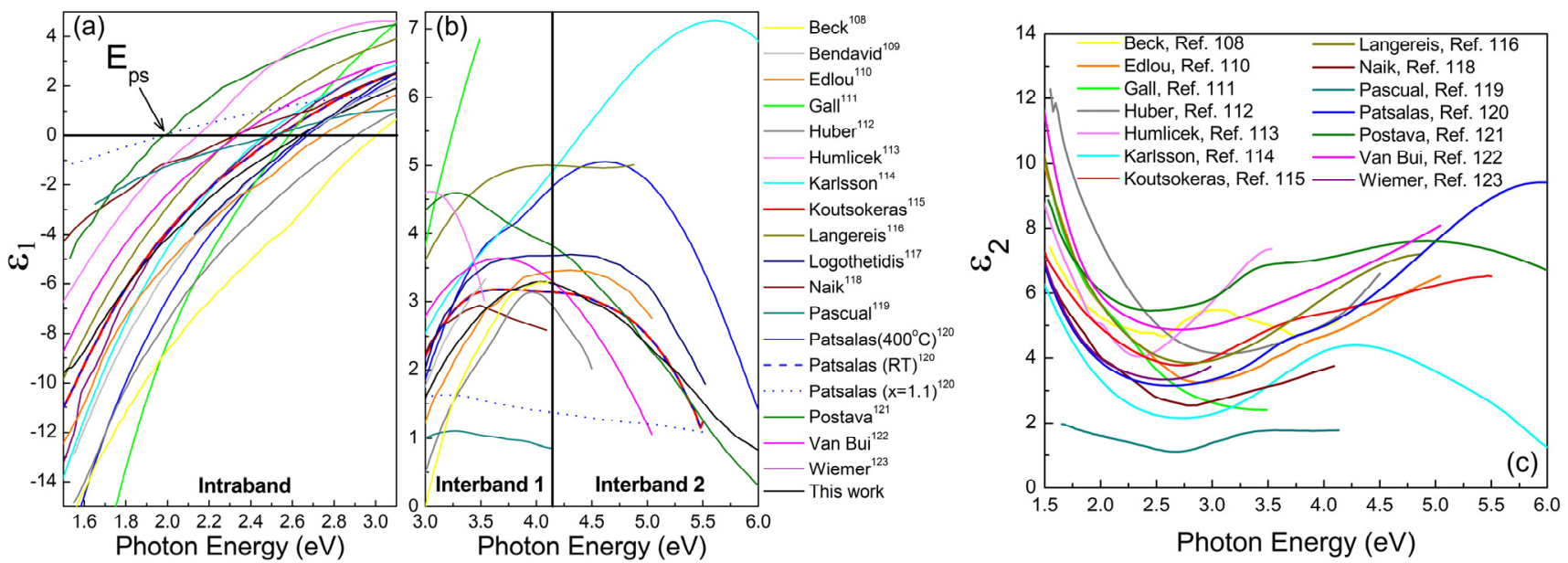

Figure 1. (a), (b) $\varepsilon_{1}$, and (c) $\varepsilon_{2}$ spectra of TiN reported by several groups worldwide. 
Table 1. The titanium nitride (TiN) spectra reviewed in this work.

\begin{tabular}{|c|c|c|c|c|c|c|c|c|c|}
\hline No & $\begin{array}{c}\text { Growth } \\
\text { Technique }\end{array}$ & Substrate & $\begin{array}{c}\text { Thickness } \\
\text { (nm) }\end{array}$ & Morphology & $\begin{array}{c}\text { Measurement } \\
\text { Technique }\end{array}$ & Instrument * & $\begin{array}{c}\text { Analysis } \\
\text { Model }\end{array}$ & Reference & Comments \\
\hline 1 & $\mathrm{~N} / \mathrm{A}$ & $\begin{array}{l}\text { Stainless } \\
\text { Steel }\end{array}$ & Opaque & $\mathrm{N} / \mathrm{A}$ & SE & RPE by SOPRA & $\mathrm{N} / \mathrm{A}$ & {$[108]$} & $\begin{array}{l}\text { Stoichiometry determined by Auger Electron } \\
\text { Spectroscopy (AES) }\end{array}$ \\
\hline 2 & FCVA & $\operatorname{Si}(100)$ & 150 & N/A & SE & RAE & $\mathrm{D}$ & [109] & $\begin{array}{l}\text { Stoichiometry } \mathrm{x}=0.97 \text { determined by Rutherford } \\
\text { Backscattering (RBS) }\end{array}$ \\
\hline 3 & $\begin{array}{l}\text { Magnetron } \\
\text { Sputtering }\end{array}$ & Fused Silica & Opaque & $\mathrm{N} / \mathrm{A}$ & VASE & N/A & $\mathrm{D}+1 \mathrm{~L}$ & {$[110]$} & Stoichiometry determined by RBS \\
\hline 4 & UHV Sputtering & $\mathrm{MgO}(100)$ & 200 & Epitaxial & ORS & Perkin Elmer & $\mathrm{D}+2 \mathrm{~L}$ & [111] & $\begin{array}{l}\text { (100) Oriented identified by X-Ray Diffrcation } \\
\text { (XRD); composition determined by RBS and X-Ray } \\
\text { Photoelectron Spectroscopy (XPS); ORS measure-ments } \\
\text { acquired using an integrating sphere; ORS normalization } \\
\text { was performed via a Si(100) wafer }\end{array}$ \\
\hline 5 & Me-PIII & $\operatorname{Si}(100)$ & $100-500$ & Polycrystalline & SE & RAE & $\mathrm{D}+\mathrm{iL}$ & [112] & $\begin{array}{l}\text { Stoichiometry } \mathrm{x}=0.95 \text { determined by Elastic Recoil } \\
\text { Detection Analysis (ERDA); crystal structure } \\
\text { identified by XRD }\end{array}$ \\
\hline 6 & IBAD & $\operatorname{Si}(100)$ & $50-100$ & Polycrystalline & VASE & RAE & $\mathrm{D}+1 \mathrm{~L}$ & [113] & $\begin{array}{l}\text { Stoichiometry determined by XPS and RBS; crystal } \\
\text { structure identified by XRD; existent O impurities }\end{array}$ \\
\hline 7 & CVD & Polished Mo & $\sim 1000$ & Polycrystalline & ORS & Perkin Elmer & $\mathrm{D}+1 \mathrm{~L}$ & [114] & $\begin{array}{l}\text { Used } \mathrm{TiCl}_{4}, \mathrm{H}_{2} \text {, and } \mathrm{N}_{2} \text { precursors; stoichiometry } \\
\text { close to } 1 \text { determined by Electron Probe } \\
\text { Microanalysis (EPMA) and by the cubic lattice size } \\
(0.424 \mathrm{~nm}) \text { determined by } \mathrm{XRD} \text {; no } \mathrm{Cl} \text { impurities; } \\
\mathrm{C} \text { impurities }<0.2 \% \mathrm{wt} \text {; Normalization of the spectra } \\
\text { was performed via an evaporated } \mathrm{Al} \text { mirror; } \\
\text { Reflectivity spectra combined with Kramers-Kronig } \\
\text { analysis to extract } \varepsilon_{1}, \varepsilon_{2}\end{array}$ \\
\hline 8 & DIBS & $\operatorname{Si}(100)$ & $>300$ & $\begin{array}{c}\text { Globular } \\
\text { polycrystalline }\end{array}$ & VASE & RPE by SOPRA & $\mathrm{D}+2 \mathrm{~L}$ & [115] & $\begin{array}{l}\text { Stoichiometry } \mathrm{x}=1 \text { determined by AES } \\
\text { and XPS; crystal structure identified by XRD }\end{array}$ \\
\hline
\end{tabular}


Table 1. Cont.

\begin{tabular}{|c|c|c|c|c|c|c|c|c|c|}
\hline No & $\begin{array}{c}\text { Growth } \\
\text { Technique }\end{array}$ & Substrate & $\begin{array}{l}\text { Thickness } \\
\text { (nm) }\end{array}$ & Morphology & $\begin{array}{c}\text { Measurement } \\
\text { Technique }^{\#}\end{array}$ & Instrument * & $\begin{array}{c}\text { Analysis } \\
\text { Model }\end{array}$ & Reference & Comments \\
\hline 9 & ALD & $\begin{array}{l}\text { H-terminated } \\
\qquad \mathrm{Si} \\
\end{array}$ & $>100$ & Polycrystalline & in situ $\mathrm{SE}$ & $\begin{array}{l}\text { RCE by J.A. } \\
\text { Woolam }\end{array}$ & $\mathrm{D}+2 \mathrm{~L}$ & {$[116]$} & Used $\mathrm{TiCl}_{4}, \mathrm{H}_{2}$, and $\mathrm{N}_{2}$ precursors; $\mathrm{x}<1$ \\
\hline 10 & $\begin{array}{l}\text { Magnetron } \\
\text { Sputtering }\end{array}$ & $\mathrm{Ti} / \mathrm{Si}(100)$ & 70 & $\begin{array}{c}\text { Columnar } \\
\text { Polycrystalline } \\
\end{array}$ & in situ $\mathrm{SE}$ & $\begin{array}{l}\text { PME by } \\
\text { JY-Horiba }\end{array}$ & N/A & {$[117]$} & $\begin{array}{l}\text { Microstructure identified by Transmission Electron } \\
\text { Microscopy; no information on stoichiometry }\end{array}$ \\
\hline 11 & $\begin{array}{l}\text { Magnetron } \\
\text { Sputtering }\end{array}$ & c-Sapphire & 30 & Epitaxial & VASE & $\begin{array}{c}\text { RCE by J.A. } \\
\text { Woolam }\end{array}$ & $\mathrm{D}+1 \mathrm{~L}$ & {$[118]$} & $\begin{array}{l}\text { The TiN[111]/ } \mathrm{Al}_{2} \mathrm{O}_{3}[0006] \text { epitaxy } \\
\text { was confirmed by XRD }\end{array}$ \\
\hline 12 & PECVD & Glass & Opaque & N/A & SE & RAE & $\mathrm{N} / \mathrm{A}$ & [119] & $\begin{array}{l}\text { Used } \mathrm{TiCl}_{4}, \mathrm{H}_{2} \text {, and } \mathrm{N}_{2} \text { precursors; no information on } \\
\text { composition and structure }\end{array}$ \\
\hline 13 & $\begin{array}{l}\text { Magnetron } \\
\text { Sputtering }\end{array}$ & $\operatorname{Si}(100)$ & $>100$ & Polycrystalline & in situ $\mathrm{SE}$ & $\begin{array}{l}\text { PME by } \\
\text { JY-Horiba }\end{array}$ & $\mathrm{D}+2 \mathrm{~L}$ & {$[120]$} & $\begin{array}{l}\text { Growth at } 400{ }^{\circ} \mathrm{C}, \mathrm{V}_{\mathrm{b}}=-100 \mathrm{~V} \text {; Stoichiometry } \\
\text { close to } 1 \text { confirmed by XPS; crystal structure and } \\
\text { (100) texture identified by XRD }\end{array}$ \\
\hline 14 & $\begin{array}{l}\text { Magnetron } \\
\text { Sputtering }\end{array}$ & $\operatorname{Si}(100)$ & $>100$ & Polycrystalline & in situ $\mathrm{SE}$ & $\begin{array}{l}\text { PME by } \\
\text { JY-Horiba }\end{array}$ & $\mathrm{D}+2 \mathrm{~L}$ & {$[120]$} & $\begin{array}{l}\text { Growth at RT and Bias voltage of }-120 \mathrm{~V} \text {; } \\
\text { Stoichiometry } \mathrm{x}=1 \text { determined by XPS; crystal } \\
\text { structure and (100) texture identified by XRD }\end{array}$ \\
\hline 15 & $\begin{array}{l}\text { Magnetron } \\
\text { Sputtering }\end{array}$ & $\operatorname{Si}(100)$ & $>100$ & $\begin{array}{c}\text { Columnar } \\
\text { Polycrystalline }\end{array}$ & in situ $\mathrm{SE}$ & $\begin{array}{l}\text { PME by } \\
\text { JY-Horiba }\end{array}$ & $\mathrm{D}+2 \mathrm{~L}$ & {$[120]$} & $\begin{array}{l}\text { Growth at } \mathrm{RT} \text { and } \mathrm{V}_{\mathrm{b}}=-20 \mathrm{~V} \text {; Stoichiometry } \\
\mathrm{x}=1.12 \text { determined by XPS; crystal structure and } \\
\text { (111) texture identified by XRD }\end{array}$ \\
\hline 16 & Sputtering & $\begin{array}{l}\text { Thick thermal } \\
\qquad \mathrm{SiO}_{2}\end{array}$ & 107.1 & N/A & ORS & Shimadzu & $\mathrm{D}+2 \mathrm{~L}$ & {$[121]$} & Spectral normalization was performed via a Si wafer \\
\hline
\end{tabular}


Table 1. Cont.

\begin{tabular}{|c|c|c|c|c|c|c|c|c|c|}
\hline No & $\begin{array}{c}\text { Growth } \\
\text { Technique }\end{array}$ & Substrate & $\begin{array}{c}\text { Thickness } \\
\text { (nm) }\end{array}$ & Morphology & $\begin{array}{c}\text { Measurement } \\
\text { Technique }^{\#}\end{array}$ & Instrument * & $\begin{array}{c}\text { Analysis } \\
\text { Model }\end{array}$ & Reference & Comments \\
\hline 17 & ALD & $\begin{array}{c}100 \mathrm{~nm} \\
\text { thermal } \mathrm{SiO}_{2}\end{array}$ & 10 & N/A & in situ $\mathrm{SE}$ & $\begin{array}{l}\text { RCE by } \\
\text { J.A. Woolam }\end{array}$ & $\mathrm{D}+2 \mathrm{~L}$ & [122] & $\begin{array}{l}\text { Used } \mathrm{TiCl}_{4} \text { and } \mathrm{NH}_{3} \text { precursors; Overstoichiometry } \\
\text { determined by XPS; Existent Cl-impurities }\end{array}$ \\
\hline 18 & $\begin{array}{l}\text { Magnetron } \\
\text { Sputtering }\end{array}$ & $\operatorname{Si}(100)$ & 400 & Polycrystalline & SE & $\begin{array}{l}\text { PME by } \\
\text { JY-Horiba }\end{array}$ & $\mathrm{D}$ & [123] & $\begin{array}{l}\text { Stoichiometry } 1.03>\mathrm{x}>1 \text { determined by ERDA; } \\
\text { crystal structure identified by } \mathrm{XRD}\end{array}$ \\
\hline 19 & PLD & $\operatorname{Si}(100)$ & $>100$ & Polycrystalline & VASE & $\begin{array}{l}\text { PME by } \\
\text { JY-Horiba }\end{array}$ & $\mathrm{D}+2 \mathrm{~L}$ & This work & $\begin{array}{l}\text { Growth at Room Temperature; Stoichiometry } \mathrm{x}=1 \\
\text { determined by in situ XPS; crystal structure and } \\
\text { (111) texture identified by XRD }\end{array}$ \\
\hline 20 & $\begin{array}{l}\text { Magnetron } \\
\text { Sputtering }\end{array}$ & Glass & N/A & N/A & SE & Null Ellips. & N/A & [124] & $\begin{array}{l}\text { Measurement acquired at } 70^{\circ} \text { angle of } \\
\text { incidence and in p-polarization }\end{array}$ \\
\hline 21 & $\mathrm{~N} / \mathrm{A}$ & N/A & N/A & N/A & ORS & N/A & N/A & [125] & $\begin{array}{l}\text { Reflectivity confirmed by } a b \text { initio } \\
\text { calculations for stoichiometric TiN }\end{array}$ \\
\hline 22 & $\begin{array}{c}\text { Plasma-assisted } \\
\text { Evaporation }\end{array}$ & Si or Glass & 85 & Polycrystalline & in situ $\mathrm{SE}$ & N/A & N/A & [126] & $\begin{array}{l}\text { Reduced reflectivity values due to short } \\
\text { thickness (films not completely opaque) }\end{array}$ \\
\hline 23 & $\begin{array}{l}\text { Magnetron } \\
\text { Sputtering }\end{array}$ & $\begin{array}{c}\text { Ck35 Carbon } \\
\text { steel }\end{array}$ & N/A & $\begin{array}{c}\text { Columnar } \\
\text { Polycrystalline }\end{array}$ & SE & RAE & N/A & {$[127]$} & $\begin{array}{l}\text { Stoichiometry determined by EPMA; } \\
\text { crystal structure identified by XRD }\end{array}$ \\
\hline 24 & $\begin{array}{l}\text { Magnetron } \\
\text { Sputtering }\end{array}$ & Stainless steel & $>2000$ & Polycrystalline & ORS & Beckman & $\mathrm{D}$ & [128] & $\begin{array}{l}\text { Stoichiometry determined by EPMA; } \\
\text { crystal structure identified by XRD }\end{array}$ \\
\hline
\end{tabular}

* SE = Spectroscopic Ellipsometry, VASE = Variable-Angle Spectroscopic Ellipsometry, ORS = Normal-Incidence Optical Reflectivity Spectroscopy unless otherwise specified; * RAE = Rotating Analyzer Ellipsometer,

$\mathrm{RCE}=$ Rotating Compensator Ellipsometer, $\mathrm{RPE}=$ Rotating Polarizer Ellipsometer, PME $=$ Phase-Modulated Ellipsometer . 
Beyond $3 \mathrm{eV}$, we observe positive values of $\varepsilon 1$, which are associated with the interband absorption; these bands are also observed in the $\varepsilon_{2}$ spectra. The interband absorption, which has the form of two distinct peaks, would be solidly identified, if we considered the electron density of states (EDOS) of TiN. Figure 2 presents EDOS calculations for TiN from [82], which are based on the linear augmented plane wave (LAPW) method within the density functional theory using the Wien $2 k$ software [137] and using the Generalized Gradient Approximation (GGA) in the form given by Perdew-Burke-Ernzerhof (PBE96) [138].

The observed wide interband absorption originates from the states located $2.5-5.5 \mathrm{eV}$ below the Fermi level, which are predominantly due to $\mathrm{N}-p$ electrons. A $\mathrm{N}-p \rightarrow \mathrm{Ti}-d\left(t_{2 g}\right)$ transition is in accordance with the selection rules for photonic excitation $(\Delta l=0, \pm 1)$ and the spectral separation between the N- $p$ states and the Fermi level that intercept the $t_{2 g}$ conduction band of the metals. The cut off energy (the maximum energy below the Fermi level, where the partial EDOS of the N- $p$ states gets non-zero values) is around $2.5 \mathrm{eV}$ and defines the threshold at which the dielectric losses contribute to the optical repsonse of TiN. These dielectric losses have a severe impact on the optical reflectivity spectra of TiN at normal incidence, as shown in Figure 3.

At around $3.5 \mathrm{eV}$ below the Fermi level, there is the local minimum $E_{1}$ in the N-p band; this is in excellent agreement with most of the experimental obsrevations presented in Figure 1b,c. The global maximum of $\varepsilon_{2}$, which is defined as the spectral separation between the EDOS maximum of the N-p and the Fermi level defines the second absorption band $\mathrm{E}_{2}$, which is manifested over $5 \mathrm{eV}$.

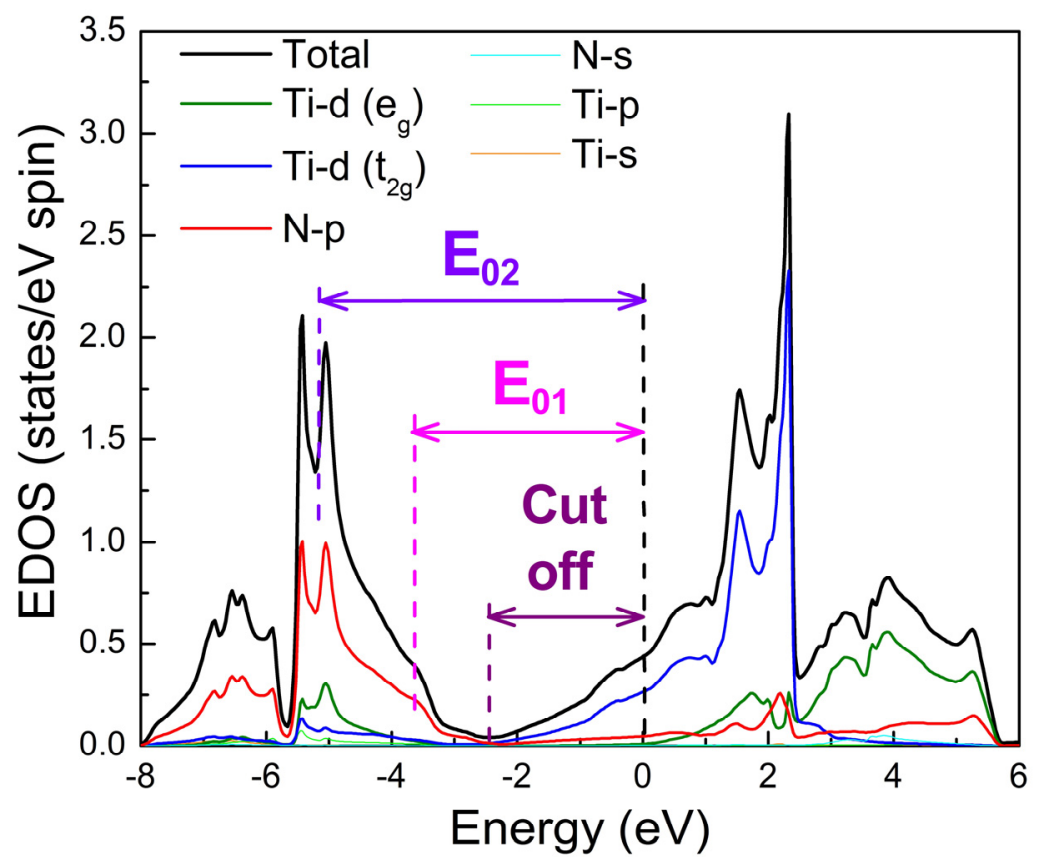

Figure 2. Electron density of states for TiN. Zero energy stands for the Fermi level and is denoted by a vertical, dashed, black line. The vertical dashed purple, magenta, and blue lines denote the cut off energy, and the energy positions of the two interband transitions $E_{01}, E_{02}$, respectively. 


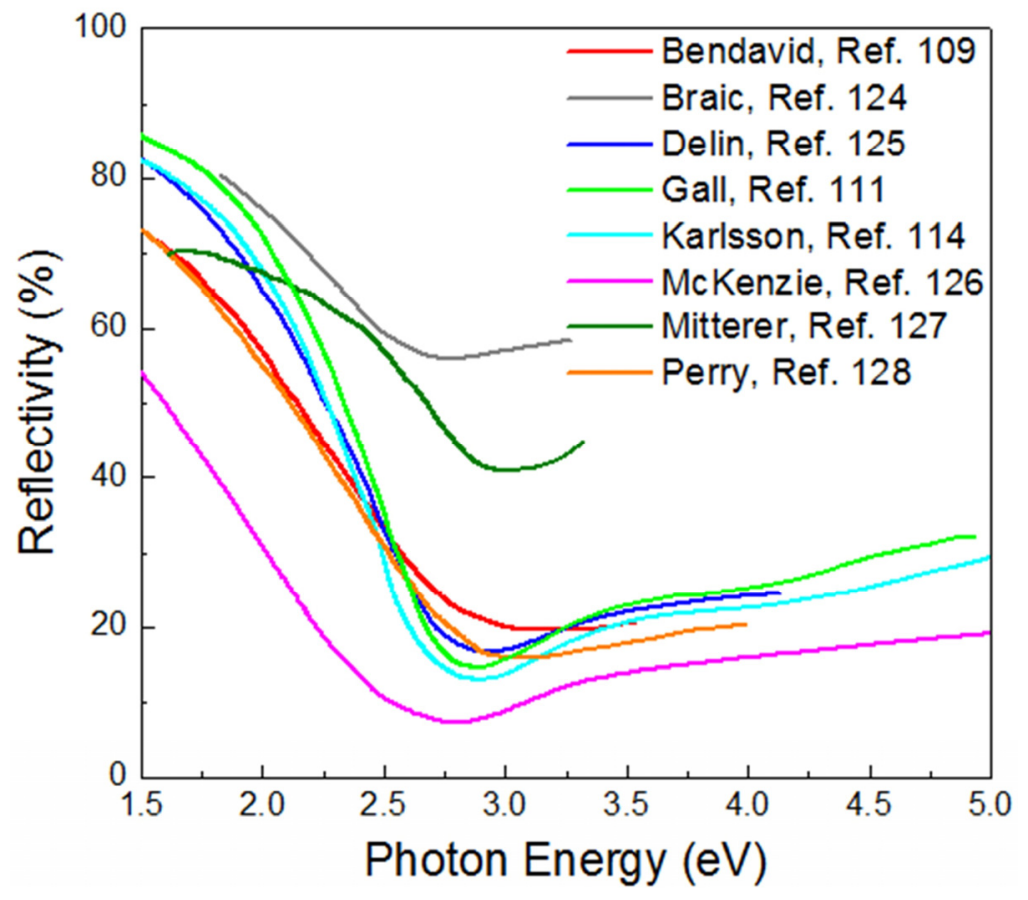

Figure 3. Optical reflectivity spectra of $\mathrm{TiN}$ at normal incidence reported by several groups. The absolute values vary due to TiN film's thickness or normalization standards; however, they all share the same qualitative features. In particular, above $2.5 \mathrm{eV}$ all spectra exhibit reduced reflectivity values due to dielectric losses.

The dielectric function of TiN films can be analyzed, via appropriate modeling in order to take into account contributions of intraband and interband transitions as described by a Drude term and several Lorentz oscillators, respectively [120,139]:

$$
\tilde{\varepsilon}(\omega)=\varepsilon_{\infty}-\frac{\omega_{\mathrm{pu}}^{2}}{\omega^{2}-i \Gamma_{\mathrm{D}} \omega}+\sum_{j=1}^{m} \frac{f_{\mathrm{j}} \cdot \omega_{\mathrm{oj}}^{2}}{\omega_{\mathrm{oj}}^{2}-\omega^{2}+i \gamma_{\mathrm{j}} \omega}
$$

In Equation (2) $\varepsilon_{\infty}$ is a background constant, larger than unity, which is due to higher-energy contributions (beyond the experimental spectral range) referring to transitions that are not taken into account by the Lorentz term(s). Each of the Lorentz oscillators is located at an energy position $E_{\mathrm{oj}}=\hbar \omega_{\mathrm{oj}}$, with strength $f_{\mathrm{j}}$ and damping (broadening) factor $\gamma_{\mathrm{j}}$.

The Drude term is characterized by the unscreened plasma energy $E_{\mathrm{pu}}=\hbar \omega_{\mathrm{pu}}$ and the damping factor $\Gamma_{\mathrm{D}} E_{\mathrm{pu}}$ depends on the concentration of the conduction electrons in the film and is defined by the relation $[120,139]$ :

$$
E_{\mathrm{pu}}=\hbar \omega_{\mathrm{pu}}, \omega_{\mathrm{pu}}=\sqrt{\frac{N e^{2}}{\varepsilon_{o} m^{*}}}
$$

where $\mathrm{N}$ is the conduction electron density, e is the electron charge, $\varepsilon_{0}$ is the permittivity of free space and $\mathrm{m}^{*}$ is the electron effective mass, in SI units. Since $E_{\mathrm{pu}}$ is directly correlated with the conduction electron density, it can be used to quantify the metallic character of the TiN. $\Gamma_{\mathrm{D}}$ is due to the scattering 
of electrons and according to the free-electron theory it is related to the electron relaxation time through the relation $[120,139]$ :

$$
\tau_{\mathrm{D}}=\frac{\hbar}{\Gamma_{\mathrm{D}}(e V)}
$$

The $\omega_{\mathrm{pu}}$ and $\tau_{\mathrm{D}}$ are also closely related with the electrical resistivity $(\rho)$. The relaxation time of conduction electrons is associated with the film resistivity through the relation $[120,140]$ :

$$
\tau_{\mathrm{D}}=\frac{m^{*}}{\rho N e^{2}} \text { or } \rho=\left(\frac{4 \pi}{\hbar}\right) \cdot \frac{\Gamma_{\mathrm{D}}}{\omega_{\mathrm{pu}}^{2}}
$$

Changes of $\omega_{\mathrm{pu}}$ may be attributed, according to Equation (7), either to changes in free electron density or to the electron effective mass [19]. In any case, the increase of $\omega_{\mathrm{pu}}$ is strongly correlated with the enhancement of TiN metallic character expressed in terms of electrical resistivity.

Based on the above, the relaxation time can be used to calculate the mean free path (MFP) of the conduction electrons in TiN. The MFP for nanocrystalline $\mathrm{TiN}$ or for $\mathrm{TiN}$ nanostructures and nanoparticles is mostly due to scattering of electrons at the particle surfaces. MFP can be expressed, in terms of the relaxation time and the velocity $\left(v_{\mathrm{F}}\right)$ at the Fermi surface [141]:

$$
\frac{1}{\tau_{\mathrm{D}}}=\frac{1}{\tau_{\text {bulk }}}+\frac{v_{\mathrm{F}}}{\mathrm{MFP}} \Leftrightarrow \Gamma_{\mathrm{D}}=\Gamma_{\text {bulk }}+\frac{v_{\mathrm{F}}}{\mathrm{MFP}} \Leftrightarrow \mathrm{MFP}=\frac{v_{\mathrm{F}}}{\Gamma_{\mathrm{D}}-\Gamma_{\text {bulk }}}
$$

where $\tau_{\text {bulk }}$ is the electron relaxation time of the bulk TiN. The velocity at the Fermi surface is calculated according to the free electron model through the relation $[120,140]$ :

$$
v_{\mathrm{F}}=\left(\frac{\hbar}{m^{*}}\right) \cdot\left(3 \pi^{2} N\right)^{1 / 3}=\hbar\left(\frac{0.75 \pi}{\left(m^{*} e\right)^{2}}\right)^{1 / 3} \cdot \omega_{\mathrm{pu}}^{2 / 3}
$$

The velocity of thermal movement of electrons $\left(v_{\mathrm{T}}=\left(\mathrm{k}_{\mathrm{B}} \mathrm{T} / 2 \mathrm{~m}^{*}\right)^{1 / 2}=4.77 \times 10^{6} \mathrm{~cm} / \mathrm{s}\right)$ is smaller by two orders of magnitude than $\mathrm{VF}_{\mathrm{F}}$ and thus it can be reasonably neglected in the calculation of MFP:

$$
\operatorname{MFP}=\left(\frac{0.75 \pi}{\left(m^{*} e\right)^{2}}\right)^{1 / 3} \cdot \frac{\hbar^{2} \omega_{\mathrm{pu}}^{2 / 3}}{\Gamma_{\mathrm{D}}-\Gamma_{\text {bulk }}}
$$

The $\Gamma_{\text {bulk }}$ for TiN was determined to be $0.13 \mathrm{eV}$ by ab initio calculations [82]; note that in [120], the MFP was determined using the crude assumption $\Gamma_{\text {bulk }}=0 \mathrm{eV}$, because at that time there were no relevant data available for $\Gamma_{\text {bulk, }}$ therefore, the reported values in Table 2 are more realistic approximations of the real conduction electron MFP for TiN.

In this work we fitted most of the spectra presented in Figure 1 by Equation (6) using the Drude term and two Lorentz oscillators $(\mathrm{m}=2)$, which simulate the contributions of the two interband transitions, $E_{01}, E_{02}$ defined in Figure 2, in order to provide a quantitative comparison; we call this model D2L. Spectra of non identified thickness or reference optical data of the substrate are excluded from the comparison. 
Representative experimental dielectric function spectra along with the corresponding D2L fit results and the convolution to the individual contributions of the Drude term and the two Lorentz oscillators for two TiN films exhibiting high (blue symbols and lines) and low (red symbols and lines) Eps values are presented in Figure 4. The results of the fits, as well as the values of resistivity and MFP [according to Equations (9) and (12)], are presented in Table 2. Note that the presented resistivity values are consistent with the reported resistivity acquired by electrical measurements [120,142-145].
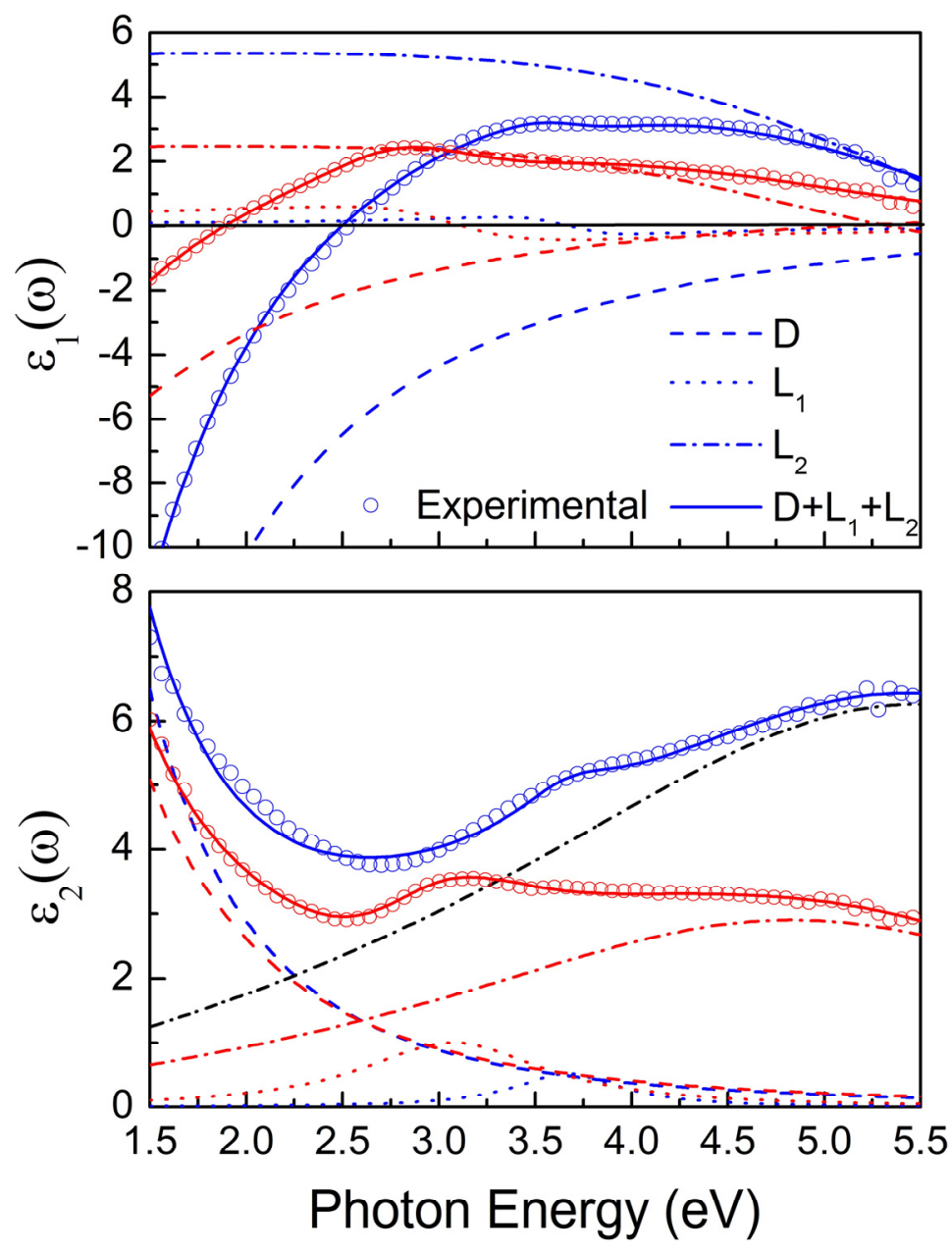

Figure 4. The experimental (open circles) and the fitted (solid lines) real $\left(\varepsilon_{1}\right)$ and the imaginary $\left(\varepsilon_{2}\right)$ parts of the dielectric function of two representative TiN films, $100 \mathrm{~nm}$ thick, deposited at RT and $\mathrm{V}_{\mathrm{b}}=-40 \mathrm{~V}$ (red points and lines), (b) $\mathrm{V}_{\mathrm{b}}=-120 \mathrm{~V}$ (blue points and lines). The individual contributions of the Drude (D) term (dashed lines) and the two Lorentz oscillators ( $\mathrm{L}_{1}, \mathrm{~L}_{2}$, dotted, and dashed-dotted lines) are also shown. The experimental data are taken from [120]. 
Table 2. The results of the Drude-Lorentz fits on the complex dielectric function spectra of TiN reported by various groups.

\begin{tabular}{|c|c|c|c|c|c|c|c|c|c|c|c|c|}
\hline \multirow{2}{*}{ Reference } & \multicolumn{2}{|c|}{ Intraband } & \multicolumn{3}{|c|}{ Interband 1} & \multicolumn{3}{|c|}{ Interband 2} & \multicolumn{2}{|c|}{ Composite } & \multicolumn{2}{|c|}{ Properties } \\
\hline & $E_{\mathrm{pu}}(\mathrm{eV})$ & $\Gamma_{d}(e V)$ & $f_{1}$ & $E_{01}(\mathrm{eV})$ & $\gamma_{1}(\mathrm{eV})$ & $f_{2}$ & $E_{02}(\mathrm{eV})$ & $\gamma_{2}(\mathrm{eV})$ & $E_{\mathrm{ps}}(\mathrm{eV})$ & $\varepsilon_{\infty}$ & MFP (nm) & $\rho(\mu \Omega \mathrm{cm})$ \\
\hline Edlou et al. [110] & 7.248 & 0.639 & 0.232 & 2.066 & 0.544 & 4.039 & 5.645 & 3.621 & 2.75 & 2.352 & 19.9 & 94 \\
\hline Gall et al. [111] & 9.766 & 0.349 & 0.395 & 2.195 & 0.816 & 5.278 & 8.228 & 4.041 & 2.59 & 8.784 & 56.5 & 28 \\
\hline Huber et al. [112] & 8.080 & 0.860 & 3.536 & 5.139 & 3.043 & N/A & $\mathrm{N} / \mathrm{A}$ & N/A & 2.90 & 2.998 & 14.9 & 102 \\
\hline Humlicek et al. [113] & 6.421 & 0.859 & 3.118 & 3.765 & 1.547 & N/A & N/A & N/A & 2.15 & 3.839 & 12.8 & 161 \\
\hline Koutsokeras et al. [115] & 7.051 & 0.629 & 0.383 & 3.713 & 1.333 & 4.349 & 5.878 & 4.282 & 2.55 & 2.129 & 20.0 & 98 \\
\hline Langereis et al. [116] & 7.210 & 0.806 & 2.685 & 4.480 & 2.644 & 1.274 & 5.355 & 0.879 & 2.32 & 3.871 & 15.0 & 120 \\
\hline Naik et al. [118] & 5.707 & 0.165 & 0.195 & 2.264 & 0.722 & 2.312 & 4.894 & 3.875 & 1.99 & 2.667 & 247.3 & 39 \\
\hline Patsalas et al. [12] $400^{\circ} \mathrm{C}, \mathrm{V}_{\mathrm{b}}=-100 \mathrm{~V}$ & 7.750 & 0.350 & 0.100 & 3.682 & 0.712 & 5.620 & 6.260 & 3.875 & 2.67 & 1.850 & 48.2 & 45 \\
\hline Patsalas et al. [120] RT, $\mathrm{V}_{\mathrm{b}}=-120 \mathrm{~V}$ & 6.926 & 0.589 & 0.183 & 3.690 & 0.943 & 4.877 & 5.967 & 4.882 & 2.65 & 1.872 & 21.5 & 95 \\
\hline Patsalas et al. [120] RT, $\mathrm{V}_{\mathrm{b}}=-40 \mathrm{~V}, \mathrm{x}=1.1$ & 4.493 & 1.379 & 0.550 & 3.761 & 2.075 & 1.639 & 6.674 & 5.553 & 1.98 & 1.198 & 5.9 & 527 \\
\hline Postava et al. [121] & 6.357 & 0.738 & 0.146 & 3.478 & 0.760 & 7.008 & 5.789 & 5.933 & 1.99 & 1.957 & 15.3 & 141 \\
\hline Wiemer et al. [123] & 7.067 & 0.438 & 4.218 & 5.084 & 3.349 & N/A & $\mathrm{N} / \mathrm{A}$ & N/A & 2.48 & 3.236 & 32.4 & 68 \\
\hline TiN by PLD, this work & 6.944 & 0.726 & 3.962 & 5.521 & 4.117 & 1.041 & 7.823 & 2.199 & 2.64 & 1.198 & 16.5 & 116 \\
\hline
\end{tabular}


Comparing the values of the various parameters as a result of the D2L models, we can conclude the following results:

(1) The maximum MFP acquired for the reported TiN films is less than $50 \mathrm{~nm}$; this value, compared with equivalent values for noble metals, can provide a measure of the size limitations for single-crystalline TiN nanoparticles, which might exhibit LSPR,

(2) $E_{\mathrm{ps}}$, which is associated with the SPP performance of TiN as we will show below, is associated only with $E_{\mathrm{pu}}$ (see also Figure 5 ) and there is no explicit relation of $E_{\mathrm{ps}}$ with any other D2L parameter. The meaning of this observation is that, despite that the screening of the plasma energy in TiN is due to the existence of the interband transitions, similar to Au, the numerical variations of these interband transitions are not strong enough to affect $E_{\mathrm{ps}}$.

(3) $E_{\mathrm{pu}}$, which is associated with the conduction electron density, is above $6.9 \mathrm{eV}$ for stoichiometric and highly conductive TiN; the same films exhibit $E_{\mathrm{ps}}$ close to $2.65 \mathrm{eV}$ as observed by Logothetidis et al. [117].

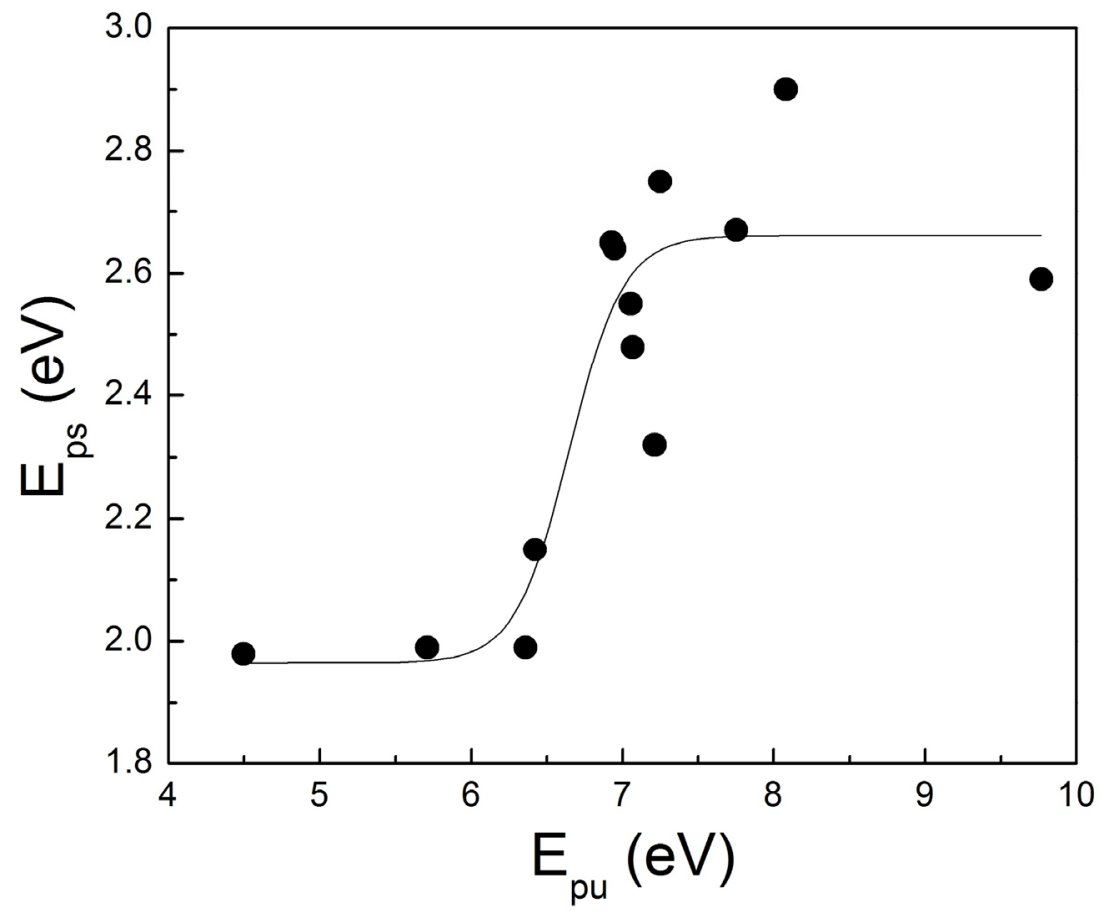

Figure 5. The correlation of screened $\left(E_{\mathrm{ps}}\right)$ and unscreened $\left(E_{\mathrm{pu}}\right)$ plasma energy for continuous TiN films resulted by the D2L analysis of the various TiN samples reported in Table 2 (the line is a guide to the eye).

\subsection{Potential of TiN for SPP Applications}

After the extensive review of the optical properties of TiN thin films, we proceed with the evaluation of the potential of TiN surfaces for applications involving SPP. SPP are electromagnetic excitations propagating across a planar conductor/dielectric interface, as a direct consequence of the coupling between the electromagnetic field of light and the resonant plasma oscillation of the conduction electrons of the conductor. Therefore, the optical and electrical properties of the conductor will have severe effects on the SPP behavior at a conductor-dielectric interface. As we have reported in 
the previous paragraphs, TiN exhibits a unique tunability of its conductivity offering great tailoring potential for SPP devices.

In order to evaluate the SPP at interfaces involving TiN as a conductor, we initially consider the TiN/AIN interface. We base this choice upon the structural and chemical compatibility of the conducting $f c c \mathrm{~B} 1-\mathrm{TiN}(111)$ and the dielectric $h c p \mathrm{w}-\mathrm{AlN}(0001)$ (note that the fundamental gap of AlN is $6.2 \mathrm{eV}$ [146]) surfaces that result in stable and sharp TiN/AIN interfaces [147-153]. The most characteristic description of the SPP across the interface is via the dispersion relation that correlates the frequency of light $\omega$ with the wave vector $k_{x}$ in the direction of propagation of SPP. The general equation that defines the aforementioned relation is the following [32]:

$$
k_{x}=\frac{\omega}{c} \sqrt{\frac{\widetilde{\varepsilon}_{\mathrm{TiN}} \cdot \tilde{\varepsilon}_{\mathrm{D}}}{\tilde{\varepsilon}_{\mathrm{TiN}}+\tilde{\varepsilon}_{\mathrm{D}}}}
$$

where $\tilde{\varepsilon}_{T i N}$ and $\tilde{\varepsilon}_{D}$ are the complex dielectric functions of TiN and the dielectric (AlN in our case), respectively, and $\mathrm{c}$ is the speed of light in vacuum. Given that the dielectric functions are inherently complex, Equation (13) should be modified to:

$$
k_{x}=\frac{\omega}{c} \operatorname{Re}\left(\sqrt{\frac{\widetilde{\varepsilon}_{\mathrm{TiN}} \cdot \tilde{\varepsilon}_{\mathrm{D}}}{\tilde{\varepsilon}_{\mathrm{TiN}}+\tilde{\varepsilon}_{\mathrm{D}}}}\right)
$$

when optical attenuation in the conductor exists. A more convenient way of writing the dispersion relation in order to be more easily compared to the experiments is:

$$
\hbar k_{x} c=\hbar \omega \cdot \operatorname{Re}\left(\sqrt{\frac{\widetilde{\varepsilon}_{\mathrm{TiN}} \cdot \tilde{\varepsilon}_{\mathrm{D}}}{\tilde{\varepsilon}_{\mathrm{TiN}}+\tilde{\varepsilon}_{\mathrm{D}}}}\right)
$$

Figure 6 presents the calculated (via Equation (15)) SPP dispersion relations at the TiN/AIN interfaces using the dielectric function spectra reported by various groups (Table 1) and exhibiting a wide range of $E_{\mathrm{ps}}$ values. The first significant observation is that in all cases the dispersion relation is characteristic of a lossy metal and getting finite extreme values of $k_{x}$ [32] due to conduction electron (due to finite $\Gamma_{D}$ values in Table 2) and dielectric (due to the existence of interband transitions) losses. This has the consequence of the existence of quasi-bound modes at which the slope of the dispersion relation is inversed. Secondly, the characteristic surface Plasmon $E_{\mathrm{sp}}$ is scaled to the screened plasma energy $E_{\mathrm{ps}}$ of TiN (i.e., the energy where the actual $\varepsilon_{1}$ gets zero value) and not to the unscreened plasma energy $E_{p u}$, which is the exclusive characteristic of the conduction electrons. This observation points out the significance of $E_{\mathrm{ps}}$ not only as a diagnostic tool [117] but also as a critical parameter for the design of plasmonic devices. In addition, Figure 7 demonstrates the SPP dispersion relations at TiN/Dielectric interfaces for various popular dielectrics and for a highly conductive, low-loss TiN film. Air can hardly sustain a SPP mode, while the SPP is stronger and gets bigger extreme $k_{x}$ values with increasing the dielectric constant of the dielectric material; of special importance is the exceptional SPP performance across the TiN/AlN and TiN/GaN interfaces which are exceptionally stable and sharp [18,147-153]. Note, however, that SPP-based devices using the TiN/GaN interface are limited to a photon energy range below $3.45 \mathrm{eV}$, which is the direct fundamental gap of GaN. 


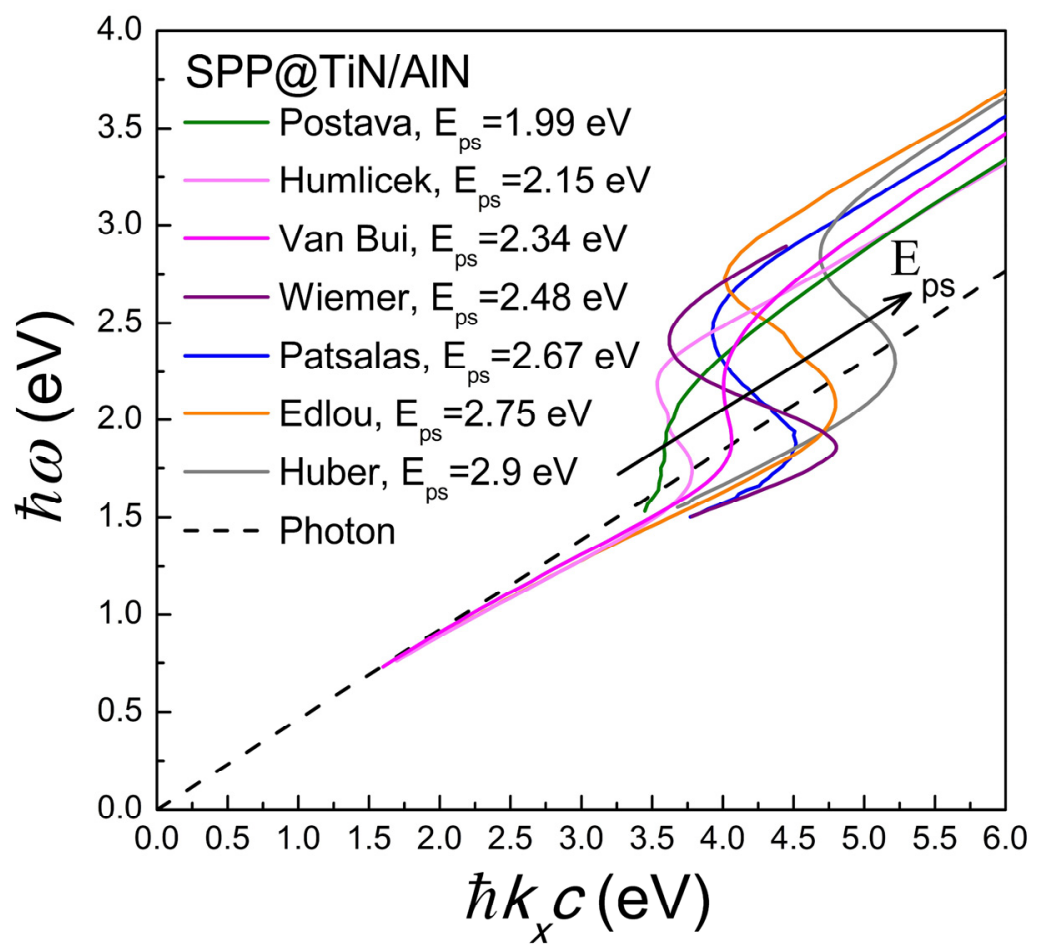

Figure 6. SPP dispersion relations at TiN/AlN interfaces for various qualities of TiN reported by different groups (according to Table 1). The dashed line is the dispersion relation of light in the dielectric.

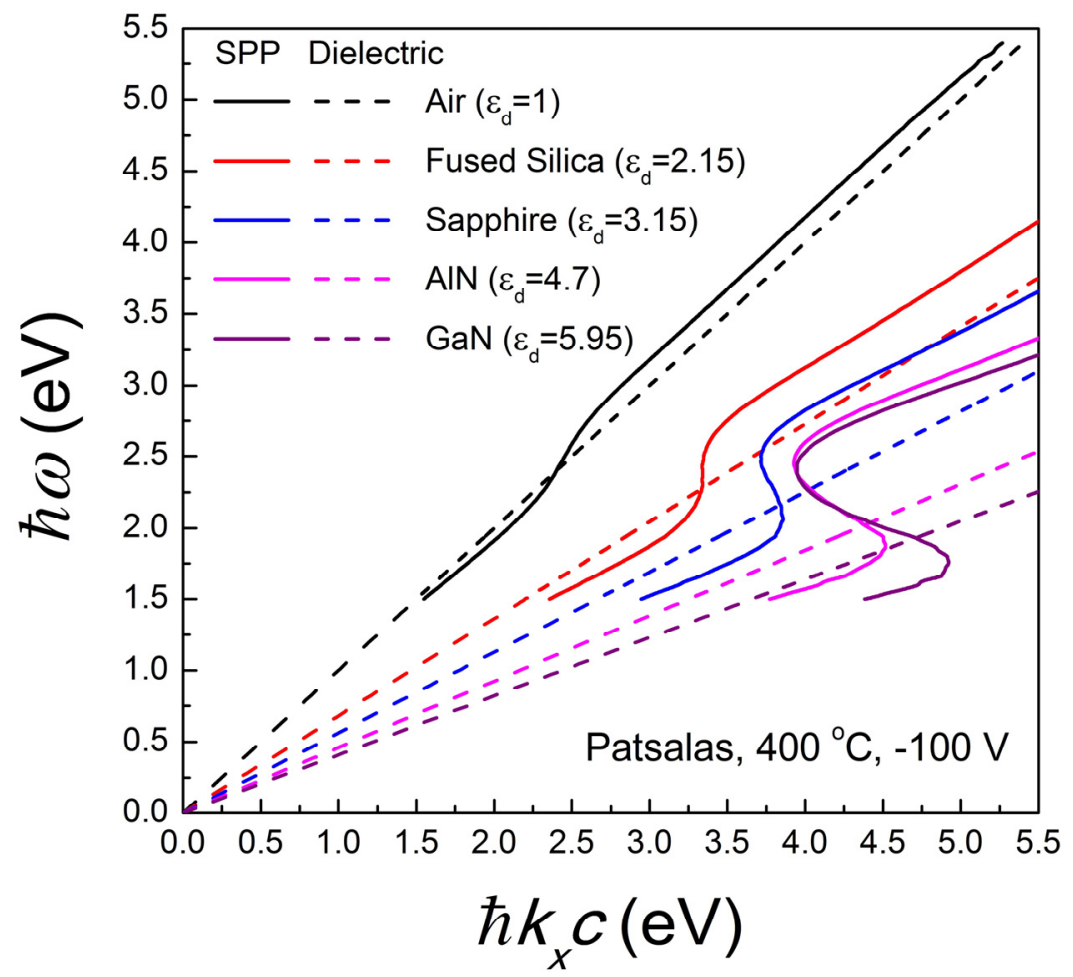

Figure 7. SPP dispersion relations at TiN/Dielectric interfaces for various popular dielectrics and for a highly conductive, low-loss TiN film. The dashed lines are the dispersion relations of light in the various dielectrics. 


\subsection{Potential of TiN for LSPR Applications}

Another field of potential applications of TiN in plasmonics is that of localized surface Plasmon resonance (LSPR) of TiN nanoparticles. The production of TiN nanoparticles was reported [141]. The use of TiN nanoparticles might be beneficial for applications such as solar harvesting and biosensing via Surface-Enhanced Raman Scattering. The optical response of TiN nanoparticle assemblies can be reasonably described by the Maxwell-Garnett Effective Medium Approximation (MG-EMA), which describes the effective optical response of a composite material consisting of a host (matrix) phase and isolated inclusions of the secondary phase [154]:

$$
\frac{\tilde{\varepsilon}-\varepsilon_{\mathrm{m}}}{\tilde{\varepsilon}+2 \varepsilon_{\mathrm{m}}}=f_{\mathrm{i}} \frac{\varepsilon_{\mathrm{i}}-\varepsilon_{\mathrm{m}}}{\varepsilon_{\mathrm{i}}+2 \varepsilon_{\mathrm{m}}}
$$

where $f_{\mathrm{i}}$ is the volume filling ratio of the inclusions, $\varepsilon_{i}$ is the reference dielectric function of the TiN inclusions and $\varepsilon_{\mathrm{m}}$ is the reference dielectric function of the host (matrix).

Given that the MFP of conduction electrons of TiN films is less than $250 \mathrm{~nm}$ (according to the data presented in Table 2), we used directly the reported dielectric functions of TiN in MG-EMA; we also considered $\varepsilon_{\mathrm{m}}=1$ assuming air as the host medium. The $\varepsilon_{2}$ spectra of TiN nanoparticle assemblies in air with filling ratio $f_{\mathrm{TiN}}=10 \% \mathrm{vol}$ calculated by MG-EMA are presented in Figure 8. In particular, Figure 8a,b present results determined using dielectric functions retrieved from literature and covering a wide range of $E_{\mathrm{ps}}$ and $E_{\mathrm{pu}}$, or retrieved from [120], where a variety of stoichiometric TiN films of varying MFP (and consequently grain size) are reported, respectively. In all cases, strong LSPR bands are observed. The narrower and stronger band is located just above $500 \mathrm{~nm}$ and resembles the far field LSPR behavior of gold, as it is clearer presented in Figure 9; in particular, Figure 9 shows the spectra of (a) the real $\varepsilon_{1}$ and imaginary $\varepsilon_{2}$ parts of the dielectric function, (b) the refractive index $n$ and the extinction coefficient $k$, which are associated with $\varepsilon_{1}$ and $\varepsilon_{2}$ via the relations $\varepsilon_{1}=n^{2}-k^{2}$ and $\varepsilon_{2}=2 n k$; and (c) the absorption coefficient $\alpha=4 \pi k / \lambda$, of nanoparticle assemblies of TiN (from [120]) and $40 \mathrm{~nm}$ Gold. Gold exhibits higher quality factor of LSPR $[\lambda / \Delta \lambda(\mathrm{FWHM})]$ but higher dielectric losses at short wavelengths than TiN.

The spectral variation of the LSPR band of TiN nanoparticles extends to an exceptional range, which covers almost the whole visible range in expense, however, of the strength of the LSPR bands. This observation confirms and supports the great potential and perspectives of TiN plasmonic nanostructures reported recently [155]. The variation of the maximum value of $\varepsilon_{2}$ at the LSPR wavelength $v s$. the LSPR wavelength exhibits a distinct maximum above $500 \mathrm{~nm}$ (Figure 10, red symbols), in contrast to the monotonous increase of max- $\varepsilon_{2}$ with the LSPR wavelength observed for $\mathrm{Ag}$ nanoparticles [156]. Finally, the importance of $E_{\mathrm{ps}}$ is also demonstrated for the case of LSPR, as well. Indeed, the spectral location of LSPR of TiN nanoparticles is straightly scaled with $E_{\mathrm{ps}}$ as it is demonstrated in Figure 10 (blue symbols). 

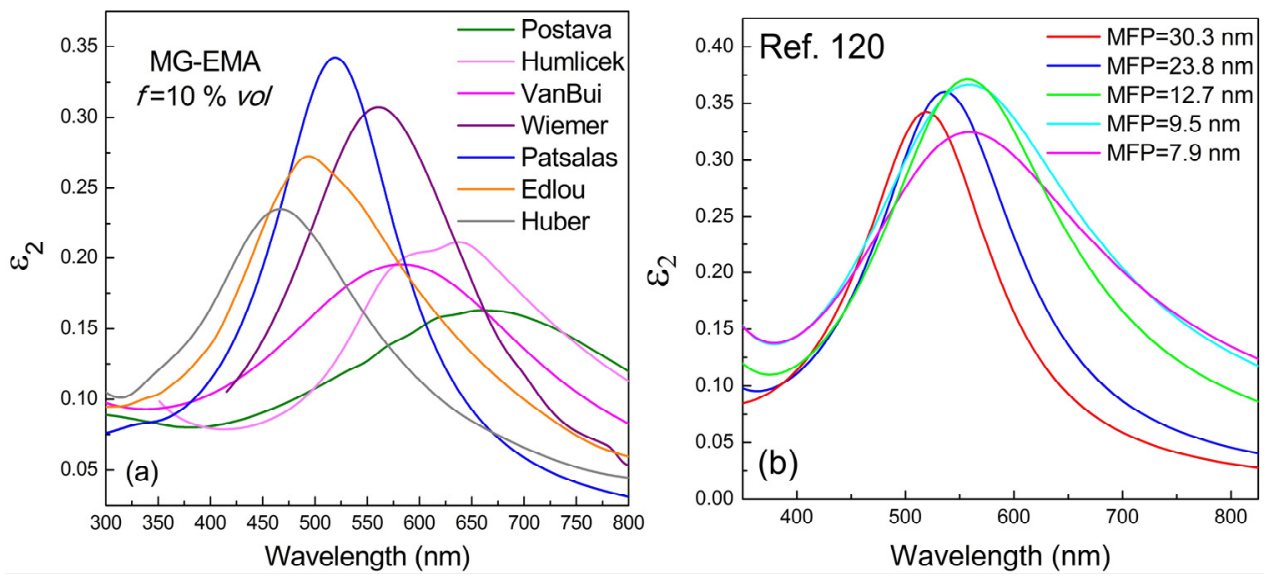

Figure 8. $\varepsilon_{2}$ spectra of TiN nanoparticles in air calculated by MG-EMA using TiN dielectric functions retrieved from (a) the literature, and (b) [120], where a variety of stoichiometric TiN films of varying MFP are reported.
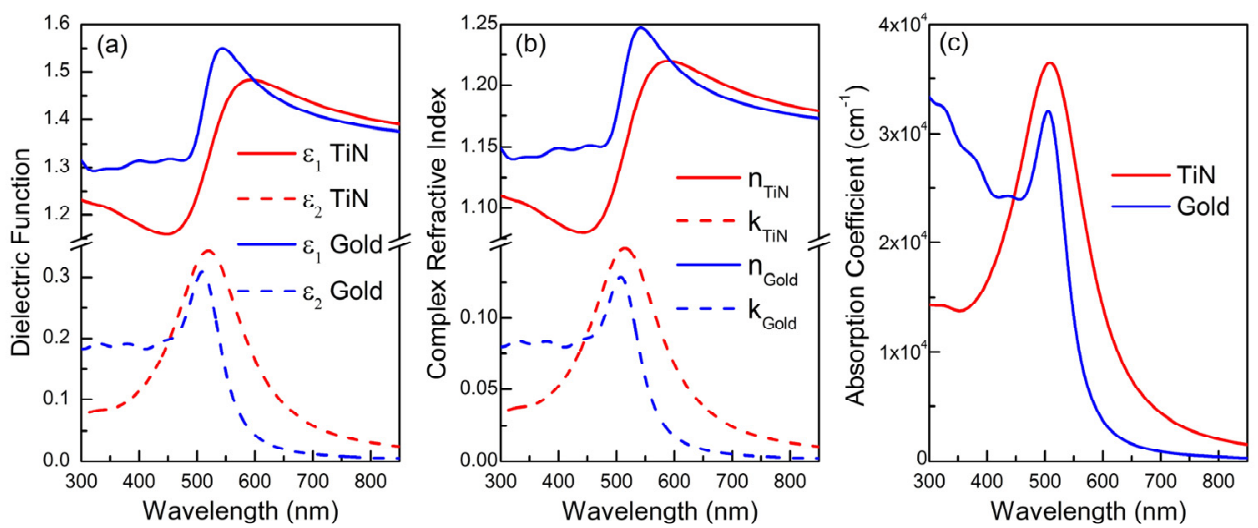

Figure 9. Comparison of the spectra of (a) the real $\varepsilon_{1}$ and imaginary $\varepsilon_{2}$ parts of the dielectric function; (b) the refractive index $\mathrm{n}$ and the extinction coefficient $k$; and (c) the absorption coefficient of nanoparticle assemblies of TiN (from [120]) and $40 \mathrm{~nm}$ Gold.

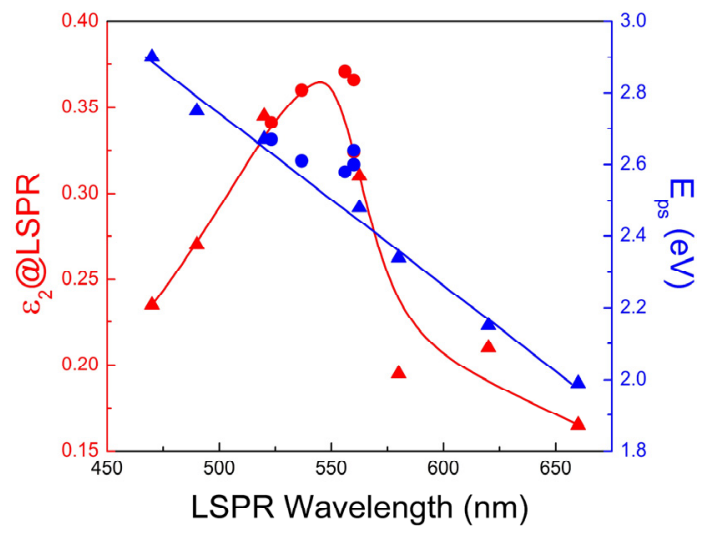

Figure 10. $\varepsilon_{2}$ value at LSPR wavelength (red symbols) and the $E_{\mathrm{ps}}$ parameter (blue symbols) $v s$. the LSPR wavelength. All reported values are deduced by the $\varepsilon_{2}$ spectra of TiN nanoparticles in air calculated by MG-EMA using TiN dielectric functions retrieved from the literature (triangles), and [120] (disks) and presented in Figure 8. The lines are guides to the eye. 


\section{Conclusions}

In this work, we reviewed the optical properties of TiN films grown by various techniques and on various substrates as reported by several research groups worldwide. The electronic conductivity of TiN is due to the semi filled $d$-band of Ti. Its optical properties are affected by the co-existence of Ti- $d$ conduction (free) electrons and the N-p to Ti- $d$ interband transitions. Consequently, the dielectric function spectra of TiN can be fitted by a combined model which consists of a Drude term that describes the conduction electrons, and two Lorentz oscillators that describe the interband transitions. The phenomenological parameter $E_{\mathrm{ps}}$, which has no explicit physical meaning, is associated mostly with the unscreened plasma energy $E_{\mathrm{pu}}$ of the conduction electrons of TiN and determines the SPP and LSPR characteristics of TiN plasmonic devices. In particular, the SPP performance of TiN/AlN and TiN/GaN planar interfaces is remarkable. In addition, varying the composition and microstructural characteristics of TiN results in variations of $E_{\mathrm{ps}}$, which in its turn can be used to tailor the spectral position of LSPR emerging from assemblies of TiN nanoparticles. However, the spectral variation of TiN's LSPR comes at expense of the LSPR strength. The strongest LSPR observed for TiN nanoparticles is located above $500 \mathrm{~nm}$ and resembles that of gold

\section{Author Contributions}

Panos Patsalas decided the scope and contents of the paper, had the overview of the work and wrote the paper; Nikolaos Kalfagiannis and Spyros Kassavetis gathered and evaluated the optical spectra from the literature; Nikolaos Kalfagiannis performed the modeling and did the quantitative analysis of the optical spectra.

\section{Conflicts of Interest}

The authors declare no conflict of interest.

\section{References}

1. Perry, A.J. A contribution to the study of Poisson's ratios and elastic constants of TiN, ZrN and HfN. Thin Solid Films 1990, 193-194, 463-471.

2. Kuzel, R., Jr.; Cerny, R.; Valvoda, V.; Blomberg, M.; Merisalo, M. Complex XRD microstructural studies of hard coatings applied to PVD-deposited TiN films. Thin Solid Films 1994, 247, 64-78.

3. Sproul, W.D.; Rudnik, P.J.; Gogol, C.A. The effect of target power on the nitrogen partial pressure level and hardness of reactively sputtered titanium nitride coatings. Thin Solid Films 1989, 171, 171-181.

4. Gammer, K.; Stoiber, M.; Wagner, J.; Hutter, H.; Kullmer, R.; Mitterer, C. Investigations on the effects of plasma-assisted pre-treatment for plasma-assisted chemical vapour deposition TiN coatings on tool steel. Thin Solid Films 2004, 461, 277-281.

5. Östling, M.; Nygren, S.; Petersson, C.S.; Norström, H.; Buchta, R.; Blom, H.-O.; Berg, S. A comparative study of the diffusion barrier properties of TiN and ZrN. Thin Solid Films 1986, $145,81-88$. 
6. Kaloyeros, A.E.; Eisenbraun, E. Ultrathin diffusion barriers/liners for gigascale copper metallization. Annu. Rev. Mater. Sci. 2000, 30, 363-385.

7. Chen, G.S.; Huang, S.C.; Chen, S.T.; Yang, T.J.; Lee, P.Y.; Jou, J.H.; Lin, T.C. An optimal quasisuperlattice design to further improve thermal stability of tantalum nitride diffusion barriers. Appl. Phys. Lett. 2000, 76, 2895-2897.

8. Zeng, Y.; Russell, S.W.; McKerrow, A.J.; Chen, L.; Alford, T.L. Effectiveness of Ti, TiN, Ta, $\mathrm{TaN}$, and $\mathrm{W}_{2} \mathrm{~N}$ as barriers for the integration of low-k dielectric hydrogen silsesquioxane. $J$. Vac. Sci. Technol. B 2000, 18, 221-230.

9. Aouadi, S.M.; Shreeman, P.K.; Williams, M. Real-time spectroscopic ellipsometry study of ultrathin diffusion barriers for integrated circuits. J. Appl. Phys. 2004, 96, 3949-3955.

10. Randhawa, H. Hard coatings for decorative applications. Surf. Coat. Technol. 1988, 36, 829-836.

11. Budke, E.; Krempel-Hesse, J.; Maidhof, H.; Schüssler, H. Decorative hard coatings with improved corrosion resistance. Surf. Coat. Technol. 1999, 112, 108-113.

12. Niyomsoan, S.; Grant, W.; Olson, D.L.; Mishra, B. Variation of color in titanium and zirconium nitride decorative thin films. Thin Solid Films 2002, 415, 187-194.

13. Petrov, I.; Barna, P.B.; Hultman, L.; Greene, J.E. Microstructural evolution during film growth. J. Vac. Sci. Technol. A 2003, 21, S117-S128.

14. Patsalas, P.; Logothetidis, S. Interface properties and structural evolution of TiN/Si and TiN/GaN heterostructures. J. Appl. Phys. 2003, 93, 989-998.

15. Matenoglou, G.M.; Koutsokeras, L.E.; Patsalas, P. Plasma energy and work function of conducting transition metal nitrides for electronic applications. Appl. Phys. Lett. 2009, 94, 152108.

16. Koutsokeras, L.E.; Matenoglou, G.M.; Patsalas, P. Structure, electronic properties and electron energy loss spectra of transition metal nitride films. Thin Solid Films 2013, 528, 49-52.

17. Ruterana, P.; Nouet, G.; Kehagias, Th.; Komninou, Ph.; Karakostas, Th.; di Fort-Poisson, M.A.; Huet, F.; Morkoc, H. Microstructure of Ti/Al and TiN Ohmic contacts to gallium nitride. Phys. Stat. Sol. A 1999, 176, 767-771.

18. Gautier, S.; Komninou, Ph.; Patsalas, P.; Kehagias, Th.; Logothetidis, S.; Dimitriadis, C.A.; Nouet, G. Optical and electrical properties of TiN/n-GaN contacts in correlation with their structural properties. Semiconduct. Sci. Technol. 2003, 18, 594-601.

19. Patsalas, P.; Charitidis, C.; Logothetidis, S.; Dimitriadis, C.A.; Valassiades, O. Combined electrical and mechanical properties of titanium nitride thin films as metallization materials. J. Appl. Phys. 1999, 86, 5296-5298.

20. Malmros, A.; Andersson, K.; Rorsman, N. Combined TiN- and TaN temperature compensated thin film resistors. Thin Solid Films 2012, 520, 2162-2165.

21. Ernsberger, C.; Perry, A.J.; Lehman, L.P.; Miller, A.E.; Pelton, A.R.; Dabrowski, B.W. Low temperature tempering-induced changes in bulk resistivity, temperature coefficient of resistivity and stress in physically vapor-deposited TiN. Surf. Coat. Technol. 1988, 36, 605-616.

22. Hultman, L.; Ljungcrantz, H.; Hallin, C.; Janzén, E.; Sundgren, J.-E.; Pécz, B.; Wallenberg, L.R. Growth and electronic properties of epitaxial TiN thin films on $3 \mathrm{C}-\mathrm{SiC}(001)$ and $6 \mathrm{H}-\mathrm{SiC}(0001)$ substrates by reactive magnetron sputtering. J. Mater. Res. 1996, 11, 2458-2462. 
23. Dimitriadis, C.A.; Lee, J.I.; Patsalas, P.; Logothetidis, S.; Tassis, D.H.; Brini, J.; Kamarinos, G. Characteristics of $\mathrm{TiN}_{\mathrm{x}} / \mathrm{n}$-Si Schottky diodes deposited by reactive magnetron sputtering. J. Appl. Phys. 1999, 85, 4238-4242.

24. Petrov, I.; Hultman, L.; Helmersson, U.; Sundgren, J.-E.; Greene, J.E. Microstructure modification of TiN by ion bombardment during reactive sputter deposition. Thin Solid Films 1989, 169, 299-314.

25. Wagner, J.; Mitterer, C.; Penoy, M.; Michotte, C.; Wallgram, W.; Kathrein, M. The effect of deposition temperature on microstructure and properties of thermal CVD TiN coatings. Int. J. Refract. Met. Hard Mater. 2008, 26, 120-126.

26. Perry, A.J.; Strandberg, C.; Sproul, W.D.; Hofmann, S.; Ernsberger, C.; Nickerson, J.; Chollet, L. The chemical analysis of TiN films: A round robin experiment. Thin Solid Films 1987, 153, 169-183.

27. Musil, J.; Poulek, V.; Valvoda, V.; Kužel, R., Jr.; Jehn, H.A.; Baumgärtner, M.E. Relation of deposition conditions of Ti-N films prepared by d.c. magnetron sputtering to their microstructure and macrostress. Surf. Coat. Technol. 1993, 60, 484-488.

28. Abadias, G.; Tse, Y.Y. Diffraction stress analysis in fiber-textured TiN thin films grown by ion-beam sputtering: Application to (001) and mixed (001)+(111) texture. J. Appl. Phys. 2004, 95, 2414-2428.

29. Gbordzoe, S.; Kotoka, R.; Craven, E.; Kumar, D.; Wu, F.; Narayan, J. Effect of substrate temperature on the microstructural properties of titanium nitride nanowires grown by pulsed laser deposition. J. Appl. Phys. 2014, 116, 064310.

30. Evangelou, E.K.; Konofaos, N.; Aslanoglou, X.A.; Dimitriadis, C.A.; Patsalas, P.; Logothetidis, S.; Kokkoris, M.; Kossionides, E.; Vlastou, R.; Groetschel, R. Characterization of magnetron sputtering deposited thin films of TiN for use as a metal electrode on $\mathrm{TiN} / \mathrm{SiO}_{2} / \mathrm{Si}$ metal-oxide-semiconductor device. J. Appl. Phys. 2000, 88, 7192-7196.

31. Majhi, P.; Wen, H.-C.; Choi, K.; Alshareef, H.; Huffman, C.; Lee, B.H. A Systematic Study of the Influence of Nitrogen in Tuning the Effective Work Function of Nitrided Metal Gates. In Proceeding of the IEEE VLSI-TSA Int. Symp. on VLSI Technology, Hsinchu, Taiwan, 25-27 April 2005; pp. 105-106.

32. Maier, S.A. Plasmonics: Fundamentals and Applications; Springer Science and Business Media LLC: New York, NY, USA, 2007; pp. 65-87.

33. Enoch, S.; Bonod, N. Plasmonics: From Basics to Advanced Topics; Springer Science and Business Media LLC: New York, NY, USA, 2007; pp. 105-148, 151-176.

34. Berini, P.; de Leon, I. Surface plasmon-polariton amplifiers and lasers. Nat. Phot. 2012, 6, 16-24.

35. Lal, S.; Link, S.; Halas, N.J. Nano-optics from sensing to waveguiding. Nat. Phot. 2007, 1, 641-648.

36. Barnes, W.L.; Dereux, A.; Ebbesen, T.W. Surface plasmon subwavelength optics. Nature 2003, 424, 824-830.

37. Polman, A. Applied physics: Plasmonics applied. Science 2008, 322, 868-869.

38. Ozbay, E. Plasmonics: Merging photonics and electronics at nanoscale dimensions. Science 2006, 311, 189-193.

39. Brongersma, M.L.; Shalaev, V.M. The Case for Plasmonics. Science 2010, 328, 440-441. 
40. Van Duyne, R.P. Molecular Plasmonics. Science 2004, 306, 985-986.

41. Dionne, J.A.; Diest, K.; Sweatlock, L.A.; Atwater H.A. PlasMOStor: A Metal-Oxide-Si Field Effect Plasmonic Modulator. Nano Lett. 2009, 9, 897-902.

42. Lin, J.; Li, H.; Zhang, H.; Chen, W. Plasmonic enhancement of photocurrent in $\mathrm{MoS}_{2}$ field-effect-transistor. Appl. Phys. Lett. 2013, 102, 203109.

43. Wang, L.; Hu, W.; Wang, J.; Wang, X.; Wang, S.; Chen, X.; Lu, W. Plasmon resonant excitation in grating-gated AlN barrier transistors at terahertz frequency. Appl. Phys. Lett. 2012, 100, 123501.

44. Sheldon, M.T.; De Groep, J.V.; Brown, A.M.; Polman, A.; Atwater, H.A. Plasmoelectric potentials in metal nanostructures. Science 2014, 346, 828-831.

45. Anker, J.N..; Hall, W.P.; Lyandres, O.; Shah, N.C.; Zhao, J.; Van Duyne, R.P. Biosensing with plasmonic Nanosensors. Nat. Mater. 2008, 7, 442-453.

46. Zhang, B.; Kumar, R.B.; Dai, H.; Feldman, B.J. A plasmonic chip for biomarker discovery and diagnosis of type 1 diabetes. Nat. Med. 2014, 20, 948-953.

47. Zhang, R.; Zhang, Y.; Dong, Z.C.; Jiang, S.; Zhang, C.; Chen, L.G.; Zhang, L.; Liao, Y.; Aizpurua, J.; Luo, Y.; et al. Chemical mapping of a single molecule by plasmon-enhanced Raman scattering. Nature 2013, 498, 82-86.

48. Kravets, V.G.; Schedin, F.; Jalil, R.; Britnell, L.; Gorbachev, R.V.; Ansell, D.; Thackray, B.; Novoselov, K.S.; Geim, A.K.; Kabashin, A.V.; et al. Singular phase nano-optics in plasmonic metamaterials for label-free single-molecule detection. Nat. Mater. 2013, 12, 304-309.

49. De Angelis, F.; Das, G.; Candeloro, P.; Patrini, M.; Galli, M.; Bek, A. Nanoscale chemical mapping using three-dimensional adiabatic compression of surface plasmon polaritons. Nat. Nanotech. 2010, 5, 67-72.

50. Mubeen, S.; Lee, J.; Singh, N.; Krämer, S.; Stucky, G.D.; Moskovits, M. An autonomous photosynthetic device in which all charge carriers derive from surface plasmons. Nat. Nanotech. 2013, 8, 247-251.

51. Qian, K.; Sweeny, B.C.; Johnston-Peck, A.C.; Niu, W.; Graham, J.O.; Duchene, J.S.; Qiu, J.; Wang, Y.-C.; Engelhard, M.H.; Su, D.; et al. Surface plasmon-driven water reduction: Gold nanoparticle size matters, J. Am. Chem. Soc. 2014, 136, 9842-9845.

52. Wang, Z.; Yang, C.; Lin, T.; Yin, H.; Chen, P.; Wan, D.; Xu, F.; Huang, F.; Lin, J.; Xie, X.; Jiang, M. H-doped black titania with very high solar absorption and excellent photocatalysis enhanced by localized surface plasmon resonance. Adv. Funct. Mater. 2013, 23, 5444-5450.

53. Larsson, E.M.; Langhammer, C.; Zoric, I.; Kasemo, B. Nanoplasmonic Probes of Catalytic Reactions. Science 2009, 326, 1091-1094.

54. Atwater, H.A.; Polman, A. Plasmonics for Improved Photovoltaic Devices. Nat. Mater. 2010, 9 , 205-213.

55. Aubry, A.; Lei, D.Y.; Fernandez-Dominguez, A.I.; Sonnefraud Y.; Maier S.A.; Pendry J.B. Plasmonic Light-Harvesting Devices over the Whole Visible Spectrum. Nano Lett. 2010, 10, 2574-2579.

56. Pelayo García De Arquer, F.; Mihi, A.; Konstantatos, G. Molecular interfaces for plasmonic hot electron photovoltaics. Nanoscale 2015, 7, 2281-2288.

57. Gan, Q.; Bartoli, F.J.; Kafafi, Z.H. Plasmonic-enhanced organic photovoltaics: Breaking the 10\% efficiency barrier. Adv. Mater. 2013, 25, 2385-2396. 
58. Stratakis, E.; Kymakis, E. Nanoparticle-based plasmonic organic photovoltaic devices. Mater. Today 2013, 16, 133-146.

59. Kalfagiannis, N.; Karagiannidis, P.G.; Pitsalidis, C.; Panagiotopoulos, N.T.; Gravalidis, C.; Kassavetis, S.; Patsalas, P.; Logothetidis, S. Plasmonic silver nanoparticles for improved organic solar cells. Sol. Energy Mater. Sol. Cells 2012, 104, 165-174.

60. Deceglie, M.G.; Ferry, V.E.; Alivisatos, A.P.; Atwater, H.A. Design of nanostructured solar cells using coupled optical and electrical modeling. Nano Lett. 2012, 12, 2894-2900.

61. Pala, R.A.; Liu, J.S.Q.; Barnard, E.S.; Askarov, D.; Garnett, E.C.; Fan, S.; Brongersma, M.L. Optimization of non-periodic plasmonic light-trapping layers for thin-film solar cells. Nat. Commun. 2013, 4, 2095.

62. Sobhani, A.; Knight, M.W.; Wang, Y.; Zheng, B.; King, N.S.; Brown, L.V.; Fang, Z.; Nordlander, P.; Halas, N.J. Narrowband photodetection in the near-infrared with a plasmon-induced hot electron device. Nat. Commun. 2013, 4, 1643.

63. Konstantatos, G.; Sargent, E.H. Nanostructured materials for photon detection. Nat. Nanotech. 2010, 5, 391-400.

64. Chalabi, H.; Schoen, D.; Brongersma, M.L. Hot-electron photodetection with a plasmonic nanostripe antenna. Nano Lett. 2014, 14, 1374-1380.

65. Montelongo, Y.; Tenorio-Pearl, J.O.; Williams, C.; Zhang, S.; Milne, W.I.; Wilkinson, T.D. Plasmonic nanoparticle scattering for color holograms. Proc. Natl. Acad. Sci. USA 2014, 111, 12679-12683.

66. Olson, J.; Manjavacas, A.; Liu, L.; Chang, W.-S.; Foerster, B.; King, N.S.; Knight, M.W.; Nordlander, P.; Halas, N.J.; Link, S. Vivid, full-color aluminum plasmonic pixels. Proc. Natl. Acad. Sci. USA 2014, 111, 14348-14353.

67. Siozios, A.; Koutsogeorgis, D.C.; Lidorikis, E.; Dimitrakopoulos, G.P.; Kehagias, T.; Zoubos, H.; Komninou, P.; Cranton, W.M.; Kosmidis, C.; Patsalas, P. Optical Encoding by Plasmon-Based Patterning: Hard and Inorganic Materials Become Photosensitive. Nano Lett. 2012, 12, 259-263.

68. Zijlstra, P.; Chon, J.W.M.; Gu, M. Five-Dimensional Optical Recording Mediated by Surface Plasmons in Gold Nanorods. Nature 2009, 459, 410-413.

69. Wan, D.; Chen, H.-L.; Tseng, S.-C.; Wang, L.A.; Chen, Y.-P. One-Shot Deep-UV-Pulsed laser-induced photomodification of hollow metal nanoparticles for high density data storage on flexible substrates. ACS Nano 2010, 4, 165-173.

70. Sanchez-Valencia, J.R.; Toudert, J.; Borras, A.; Barranco, A.; Lahoz, R.; de la Fuente, G.F.; Frutos, F.; Gonzalez-Elipe, A.R. Selective Dichroic Patterning by Nanosecond Laser Treatment of Ag Nanostripes. Adv. Mater. 2011, 23, 848-853.

71. Asoro, M.A.; Damiano, J.; Ferreira, P.J. Size Effects on the Melting Temperature of Silver Nanoparticles: In-situ TEM Observations. Microsc. Microanal. 2009, 15, 706-707.

72. Chernyshev, A.P. Effect of Nanoparticle Size on the Onset Temperature of Surface Melting. Mater. Lett. 2009, 63, 1525-1527.

73. Alarifi, H.A.; Atiş, M.; Özdoğan, C.; Hu, A.; Yavuz, M.; Zhou, Y. Determination of Complete Melting and Surface Premelting Points of Silver Nanoparticles by Molecular Dynamics Simulation. J. Phys. Chem. C 2013, 117, 12289-12298. 
74. Matula, R.A. Electrical resistivity of copper, gold palladium and silver. J. Phys. Chem. Ref. Data 1979, 8, 1147-1298.

75. Boltasseva, A.; Atwater, H.A. Low-Loss Plasmonic Metamaterials. Science 2011, 331, 290-291.

76. Poulek, V.; Musil, J.; Valvoda, V.; Cerny, R. Microhardness of Ti-N films containing the $\varepsilon-\mathrm{Ti}_{2} \mathrm{~N}$ phase. J. Phys. D 1988, 21, 1657-1658.

77. Rauschenbach, B. Formation of compounds by high-flux nitrogen ion implantation in titanium. J. Mater. Sci. 1986, 21, 395-404.

78. Xu, M.; Wang, S.; Yin, G.; Li, J.; Zheng, Y.; Chen, L.; Jia, Y. Optical properties of cubic Ti3 $\mathrm{N}_{4}$, $\mathrm{Zr}_{3} \mathrm{~N}_{4}$, and $\mathrm{Hf}_{3} \mathrm{~N}_{4}$. Appl. Phys. Lett. 2006, 89, 151908.

79. Kroll, P. Hafnium nitride with thorium phosphide structure: Physical properties and an assessment of the Hf-N, Zr-N, and Ti-N phase diagrams at high pressures and temperatures. Phys. Rev. Lett. 2003, 90, 12550.

80. Stampfl, C.; Mannstadt, W.; Asahi, R.; Freeman, A.J. Electronic structure and physical properties of early transition metal mononitrides: Density-functional theory LDA, GGA, and screened-exchange LDA FLAPW calculations. Phys. Rev. B 2001, 63, 155106.

81. Brik, M.G.; Ma, C.-G. First-principles studies of the electronic and elastic properties of metal nitrides XN (X = Sc, Ti, V, Cr, Zr, Nb). Comp. Mater. Sci. 2012, 51, 380-388.

82. Matenoglou, G.M.; Lekka, C.E.; Koutsokeras, L.E.; Karras, G.; Kosmidis, C.; Evangelakis, G.A.; Patsalas, P. Structure and electronic properties of conducting, ternary $\mathrm{Ti}_{\mathrm{x}} \mathrm{Ta}_{1-\mathrm{x}} \mathrm{N}$ films. J. Appl. Phys. 2009, 105, 103714.

83. Hultman, L.; Barnett, S.A.; Sundgren, J.-E.; Greene, J.E. Growth of epitaxial TiN films deposited on $\mathrm{MgO}(100)$ by reactive magnetron sputtering: The role of low-energy ion irradiation during deposition. J. Cryst. Growth 1988, 92, 639-656.

84. Musil, J.; Kadlec, S.; Valvoda, V.; Kužel, R., Jr.; Černý, R. Ion-assisted sputtering of TiN films. Surf. Coat. Technol. 1990, 43-44, 259-269.

85. Sproul, W.D.; Rudnik, P.J.; Graham, M.E.; Rohde, S.L. High rate reactive sputtering in an opposed cathode closed-field unbalanced magnetron sputtering system. Surf. Coat. Technol. 1990, 43-44, 270-278.

86. Patsalas, P.; Charitidis, C.; Logothetidis, S. The effect of substrate temperature and biasing on the mechanical properties and structure of sputtered titanium nitride thin films. Surf. Coat. Technol. 2000, 125, 335-340.

87. Martin, N.; Sanjinés, R.; Takadoum, J.; Lévy, F. Enhanced sputtering of titanium oxide, nitride and oxynitride thin films by the reactive gas pulsing technique. Surf. Coat. Technol. 2001, 142-144, 615-620.

88. Mayrhofer, P.H.; Kunc, F.; Musil, J.; Mitterer, C. A comparative study on reactive and non-reactive unbalanced magnetron sputter deposition of TiN coatings. Thin Solid Films 2002, 415, 151-159.

89. Abadias, G.; Guerin, P. In situ stress evolution during magnetron sputtering of transition metal nitride thin films. Appl. Phys. Lett. 2008, 93, 111908.

90. Mahieu, S.; Depla, D. Reactive sputter deposition of TiN layers: Modelling the growth by characterization of particle fluxes towards the substrate. J. Phys. D 2009, 42, 053002.

91. Bendavid, A.; Martin, P.J.; Wang, X.; Wittling, M.; Kinder, T.J. Deposition and modification of titanium nitride by ion assisted arc deposition. J. Vac. Sci. Technol. A 1995, 13, 1658-1664. 
92. Tay, B.K.; Shi, X.; Yang, H.S.; Tan, H.S.; Chua, D.; Teo, S.Y. Effect of deposition conditions on the properties of TiN thin films prepared by filtered cathodic vacuum-arc technique. Surf. Coat. Technol. 1999, 111, 229-233.

93. Cheng, Y.H.; Tay, B.K.; Lau, S.P.; Kupfer, H.; Richter, F. Substrate bias dependence of Raman spectra for TiN films deposited by filtered cathodic vacuum arc. J. Appl. Phys. 2002, 92, 1845-1849.

94. Vepřek, S. Surface processes and rate-determining steps in plasma-induced chemical vapour deposition: Titanium nitride, boron carbide and silicon. Surf. Coat. Technol. 1990, 43-44, $154-166$.

95. Hamamura, H.; Komiyama, H.; Shimogaki, Y. TiN films prepared by flow modulation chemical vapor deposition using $\mathrm{TiCl}_{4}$ and $\mathrm{NH}_{3}$. Jap. J. Appl. Phys. 2001, 40, 1517-1521.

96. Ritala, M.; Leskelä, M.; Rauhala, E.; Jokinen, J. Atomic layer epitaxy growth of TiN thin films from $\mathrm{TiI}_{4}$ and $\mathrm{NH}_{3}$. J. Electrochem. Soc. 1998, 145, 2914-2920.

97. Hiltunen, L.; Leskelä, M.; Mäkelä, M.; Niinistö, L.; Nykänen, E.; Soininen, P. Nitrides of titanium, niobium, tantalum and molybdenum grown as thin films by the atomic layer epitaxy method. Thin Solid Films 1988, 166, 149-154.

98. Chowdhury, R.; Vispute, R.D.; Jagannadham, K.; Narayan, J. Characteristics of titanium nitride films grown by pulsed laser deposition. J. Mater. Res. 1996, 11, 1458-1469.

99. Wang, H.; Tiwari, A.; Kvit, A.; Zhang, X.; Narayan, J. Epitaxial growth of TaN thin films on $\mathrm{Si}(100)$ and Si(111) using a TiN buffer layer. Appl. Phys. Lett. 2002, 80, 2323-2325.

100. Ensinger, W.; Rauschenbach, B. Microstructural investigations on titanium nitride films formed by medium energy ion beam assisted deposition. Nucl. Inst. Meth. Phys. Res. B 1993, 80-81, 1409-1414.

101. Paulitsch, J.; Schenkel, M.; Zufraß, T.; Mayrhofer, P.H.; Münz, W.-D. Structure and properties of high power impulse magnetron sputtering and DC magnetron sputtering $\mathrm{CrN}$ and TiN films deposited in an industrial scale unit. Thin Solid Films 2010, 518, 5558-5564.

102. Håkansson, G.; Hultman, L.; Sundgren, J.-E.; Greene, J.E.; Münz, W.-D. Microstructures of TiN films grown by various physical vapour deposition techniques. Surf. Coat. Technol. 1991, $48,51-67$.

103. Karr, B.W.; Petrov, I.; Cahill, D.G.; Greene, J.E. Morphology of epitaxial TiN(001) grown by magnetron sputtering. Appl. Phys. Lett. 1997, 70, 1703-1705.

104. Li, T.Q.; Noda, S.; Komiyama, H.; Yamamoto, T.; Ikuhara, Y. Initial growth stage of nanoscaled TiN films: Formation of continuous amorphous layers and thickness-dependent crystal nucleation. J. Vac. Sci. Technol. A 2003, 21, 1717-1723.

105. Gall, D.; Kodambaka, S.; Wall, M.A.; Petrov, I.; Greene, J.E. Pathways of atomistic processes on TiN(001) and (111) surfaces during film growth: An ab initio study. J. Appl. Phys. 2003, 93, 9086-9094.

106. Patsalas, P.; Gravalidis, C.; Logothetidis, S. Surface kinetics and subplantation phenomena affecting the texture, morphology, stress, and growth evolution of titanium nitride films. J. Appl. Phys. 2004, 96, 6234-6246. 
107. Abadias, G.; Tse, Y.Y.; Guérin, Ph.; Pelosin, V. Interdependence between stress, preferred orientation, and surface morphology of nanocrystalline TiN thin films deposited by dual ion beam sputtering. J. Appl. Phys. 2006, 99, 113519.

108. Beck, U.; Reiners, G.; Urban, I.; Witt, K. Evaluation of optical properties of decorative coatings by spectroscopic ellipsometry. Thin Solid Films 1992, 220, 234-240.

109. Bendavid, A.; Martin, P.J.; Netterfield, R.P.; Kinder T.J. Characterization of the Optical Properties and Composition of TiN Thin Films by Spectroscopic Ellipsometry and X-ray Photoelectron Spectroscopy. Surf. Interf. Anal. 1996, 24, 627-633.

110. Edlou, S.M.; Simons, J.C.; Al-Jumaily, G.A.; Raouf N.A. Optical and electrical properties of reactively sputtered, TiN, ZrN, and HfN thin films. Proc. SPIE 1994, 2262, 96-106.

111. Gall1, D.; Petrov, I.; Greene J.E. Epitaxial $\mathrm{Sc}_{1-\mathrm{x}} \mathrm{Ti}_{\mathrm{x}} \mathrm{N}(001)$ : Optical and electronic transport properties. J. Appl. Phys. 2001, 89, 401-409.

112. Huber, P.; Manova, D.; Mändl, S.; Rauschenbach B. Optical characterization of TiN produced by metal-plasma immersion ion implantation. Surf. Coat. Technol. 2001, 142-144, 418-423.

113. Humlicek, J.; Nebojsa, A.; Hora, J.; Strasky, M.; Spousta, J.; Sikola T. Ellipsometry and transport studies of thin-film metal nitrides. Thin Solid Films 1998, 332, $25-29$.

114. Karlsson, B.; Shimshock, R.P.; Seraphin, B.O.; Haygarth, J.C. Optical properties of CVD-coated TiN, ZrN and HfN. Sol. Ener. Mater. 1983, 7, 401-411.

115. Koutsokeras, L.E.; Abadias, G.; Lekka, Ch.E.; Matenoglou, G.M.; Anagnostopoulos, D.F.; Evangelakis, G.A.; Patsalas, P. Conducting transition metal nitride thin films with tailored cell sizes: The case of $\delta-\mathrm{Ti}_{\mathrm{x}} \mathrm{Ta}_{1-\mathrm{x}} \mathrm{N}$. Appl. Phys. Lett. 2008, 93, 011904.

116. Langereis, E.; Heil, S.B.S.; Knoops, H.C.M.; Keuning, W.; van de Sanden, M.C.M.; Kessels, W.M.M. In situ spectroscopic ellipsometry as a versatile tool for studying atomic layer deposition. J. Phys. D 2009, 42, 073001.

117. Logothetidis, S.; Alexandrou, I.; Papadopoulos, A. In-situ spectroscopic ellipsometry to monitor the process of TiN thin films deposited by reactive sputtering. J. Appl. Phys. 1995, 77, 1043-1047.

118. Naik, G.V.; Schroeder, J.L.; Ni, X.; Kildishev, A.V.; Sands, T.D.; Boltasseva, A. Titanium nitride as a plasmonic material for visible and near-infrared wavelengths. Opt. Mater. Expr. 2012, 2, 478-489.

119. Pascual, E.; Polo, M.C.; Esteve, J.; Bertran, E. Surface reflectivity of TiN thin films measured by spectral ellipsometry. Surf. Sci. 1991, 251-252, 200-203.

120. Patsalas, P.; Logothetidis, S. Optical, electronic, and transport properties of nanocrystalline titanium nitride thin films. J. Appl. Phys. 2001, 90, 4725-4734.

121. Postava, K.; Aoyama, M.; Yamaguchi, T. Optical characterization of TiN/SiO2(1000 nm)/Si system by spectroscopic ellipsometry and reflectometry. Appl. Surf. Sci. 2001, 175-176, 270-275.

122. Van Bui, H.; Kovalgin, A.Y.; Wolters, R.A.M. On the difference between optically and electrically determined resistivity of ultra-thin titanium nitride films. Appl. Surf. Sci. 2013, 269, 45-49.

123. Wiemer, C.; Lévy, F.; Bussy, F. Determination of chemical composition and its relationship with optical properties of Ti-N and Ti-V-N sputtered thin films. Surf. Coat. Technol. 1994, 68-69, 181-187.

124. Braic, V.; Braic, M.; Pavelescu, G.; Melinte, D.; Necsoiu, D. The influence of deposition parameters on optical properties of titanium nitride thin films. Proc. SPIE 1995, 2461, 597-599. 
125. Delin, A.; Eriksson, O.; Ahuja, R.; Johansson, B.; Brooks, M.S.S.; Gasche, T.; Auluck, S.; Wills, J.M. Optical properties of the group-IVB refractory metal compounds. Phys. Rev. B 1996, $54,1673-1681$.

126. McKenzie, D.R.; McFall, W.D.; Nguyen, H.H.; Yin, Y. Production of dense and oriented structures including titanium nitride by energetic condensation from plasmas. Surf. Sci. 1996, 357-358, 954-960.

127. Mitterer, C.; Mayrhofer, P.H.; Waldhauser, W.; Kelesoglu, E.; Losbichler, P. The influence of the ion bombardment on the optical properties of $\mathrm{TiN}_{\mathrm{x}}$ and $\mathrm{ZrN}_{\mathrm{x}}$ coatings. Surf. Coat. Technol. 1998, 108-109, 230-235.

128. Perry, A.J.; Georgson, M.; Sproul, W.D.; Variations in the reflectance of TiN, ZrN and HfN. Thin Solid Films 1988, 157, 255-265.

129. Naik, G.V.; Saha, B.; Liu, J.; Saber, S.M.; Stach, E.A.; Irudayaraj, J.M.K.; Sands, T.D.; Shalaev, V.M.; Boltasseva, A. Epitaxial superlattices with titanium nitride as a plasmonic component for optical hyperbolic metamaterials. Proc. Natl. Acad. Sci. USA 2014, 111, 7546-7551.

130. Steinmüller-Nethl, D.; Kovacs, R.; Gornik, E.; Rödhammer, P. Excitation of surface plasmons on titanium nitride films: Determination of the dielectric function. Thin Solid Films 1994, 237, 277-281.

131. Naik, G.V.; Boltasseva, A.; Guan, J.; Shalaev, V.M.; Kildishev, A.V.; Li, W.; Guler, U.; Kinsey, N. Refractory Plasmonics with Titanium Nitride: Broadband Metamaterial Absorber. Adv. Mater. 2014, 26, 7959-7965.

132. Naik, G.V.; Kim, J.; Boltasseva, A. Oxides and nitrides as alternative plasmonic materials in the optical range. Opt. Mater. Expr. 2011, 1, 1090-1099.

133. Koutsokeras, L.E.; Hastas, N.; Kassavetis, S.; Valassiades, O.; Charitidis, C.; Logothetidis, S.; Patsalas, P. Electronic properties of binary and ternary, hard and refractory transition metal nitrides. Surf. Coat. Technol. 2010, 204, 2038-2041.

134. Tompkins, H.; Haber, E.A. Handbook of Ellipsometry; William Andrew Publishing: New York, NY, USA, 2005.

135. Roessler, D.M. Kramers-Kronig analysis of reflection data. Br. J. Appl. Phys. 1965, 16, 1119-1123.

136. Heavens, O.S. Optical Properties of Thin Solid Films, 2nd ed.; Dover Publications: New York, NY, USA; 1991; pp. 96-155.

137. Blaha, P.; Schwarz, K.; Madsen, G.K.H.; Kuasnicka, D.; Luitz, J. WIEN2k, Augmented Plane Wave Local Orbitals Program for Calculating Crystal Properties; Vienna University of Technology: Vienna, Austria, 2001.

138. Perdew, J.P.; Burke, K.; Ernzerhof, M. Generalized Gradient Approximation Made Simple. Phys. Rev. Lett. 1996, 77, 3865-3868.

139. Wooten, F. Optical Properties of Solids; Academic Press: New York, NY, USA, 1972.

140. Ashcroft, N.W.; Mermin, N.D. Solid State Physics; Saunders College Publishing: Orlando, FL, USA, 1976.

141. Reinholdt, A.; Pecenka, R.; Pinchuk, A.; Runte, S.; Stepanov, A.L.; Weirich, T.E.; Kreibig, U. Structural, compositional, optical and colorimetric characterization of TiN-nanoparticles. Europ. Phys. J. D 2004, 31, 69-76. 
142. Shin, C.-S.; Rudenja, S.; Gall, D.; Hellgren, N.; Lee, T.-Y.; Petrov, I.; Greene, J.E. Growth, surface morphology, and electrical resistivity of fully strained substoichiometric epitaxial TiN $\mathrm{x}_{\mathrm{x}}$ $(0.67 \leq \mathrm{x}<1.0)$ layers on $\mathrm{MgO}(001)$. J. Appl. Phys. 2004, 95, 356-362.

143. Holleck, H. Material selection for hard coatings. J. Vac. Sci. Technol. A 1986, 4, 2661-2669.

144. Williams, W.S. Transition metal carbides, nitrides, and borides for electronic applications. JOM 1997, 49, 38-42.

145. Ningthoujam, R.S.; Gajbhiye, N.S. Synthesis, electron transport properties of transition metal nitrides and applications. Prog. Mater. Sci. 2015, 70, 50-154.

146. Li, J.; Nam, K.B.; Nakarmi, M.L.; Lin, J.Y.; Jiang, H.X.; Carrier, P.; Wei, S.-H. Band Structure and Fundamental Optical Transitions in Wurtzite AlN. Appl. Phys. Lett. 2003, 83, 5163-5165.

147. Setoyama, M.; Nakayama, A.; Tanaka, M.; Kitagawa, N.; Nomura, T. Formation of cubic-AlN in TiN/AlN superlattice. Surf. Coat. Technol. 1996, 86-87, 225-230.

148. Wang, Y.Y.; Wong, M.S.; Chia, W.J., Rechner, J.; Sproul, W.D. Synthesis and characterization of highly textured polycrystalline AlN/TiN superlattice coatings. J. Vac. Sci. Technol. A 1998, $16,3341-3347$.

149. Wong, M.-S.; Hsiao, G.-Y.; Yang, S.-Y. Preparation and characterization of AlN/ZrN and AlN/TiN nanolaminate coatings. Surf. Coat. Technol. 2000, 133-134, 160-165.

150. Kim, D.-G.; Seong, T.-Y.; Baik, Y.-J. Effects of annealing on the microstructures and mechanical properties of TiN/AlN nano-multilayer films prepared by ion-beam assisted deposition. Surf. Coat. Technol. 2002, 153, 79-83.

151. Pankov, V.; Evstigneev, M.; Prince, R.H. Room-temperature fabrication of hard AlN/TiN superlattice coatings by pulsed laser deposition. J. Vac. Sci. Technol. A 2002, 20, 430-436.

152. Karimi, A.; Allidi, G.; Sanjines, R. Relative orientation of the constituents on the degree of crystallographic coherence in AlN/TiN superlattices. Surf. Coat. Technol. 2006, 201, 4062-4067.

153. Mei, F.H.; Shao, N.; Dai, J.W.; Li, G.Y. Coherent growth and superhardness effect of AlN/TiN nanomultilayers. Mater. Lett. 2004, 58, 3477-3480.

154. Maxwell-Garnett, J.C. Colours in Metal Glasses and in Metallic Films. Phil. Trans. R. Soc. Lond. A 1904, 203, 385-420.

155. Cortie, M.B.; Giddings, J.; Dowd, A. Optical properties and Plasmon resonances of titanium nitride nanostructures. Nanotechnology 2010, 21, 115201.

156. Panagiotopoulos, N.T.; Kalfagiannis, N.; Vasilopoulos, K.C.; Pliatsikas, N.; Kassavetis, S.; Vourlias, G.; Karakassides, M.A.; Patsalas, P. Self-assembled plasmonic templates produced by microwave annealing: Applications to surface-enhanced Raman scattering. Nanotechnology 2015, 26, 205603.

(C) 2015 by the authors; licensee MDPI, Basel, Switzerland. This article is an open access article distributed under the terms and conditions of the Creative Commons Attribution license (http://creativecommons.org/licenses/by/4.0/). 